NASA/TM-2008-215174

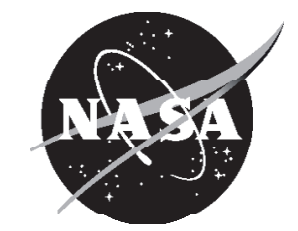

\title{
Comparison of LEWICE and GlennICE in the SLD Regime
}

William B. Wright

ASRC Aerospace Corporation, Cleveland, Ohio

Mark G. Potapczuk and Laurie H. Levinson

Glenn Research Center, Cleveland, Ohio 


\section{NASA STI Program . . . in Profile}

Since its founding, NASA has been dedicated to the advancement of aeronautics and space science. The NASA Scientific and Technical Information (STI) program plays a key part in helping NASA maintain this important role.

The NASA STI Program operates under the auspices of the Agency Chief Information Officer. It collects, organizes, provides for archiving, and disseminates NASA's STI. The NASA STI program provides access to the NASA Aeronautics and Space Database and its public interface, the NASA Technical Reports Server, thus providing one of the largest collections of aeronautical and space science STI in the world. Results are published in both non-NASA channels and by NASA in the NASA STI Report Series, which includes the following report types:

- TECHNICAL PUBLICATION. Reports of completed research or a major significant phase of research that present the results of NASA programs and include extensive data or theoretical analysis. Includes compilations of significant scientific and technical data and information deemed to be of continuing reference value. NASA counterpart of peer-reviewed formal professional papers but has less stringent limitations on manuscript length and extent of graphic presentations.

- TECHNICAL MEMORANDUM. Scientific and technical findings that are preliminary or of specialized interest, e.g., quick release reports, working papers, and bibliographies that contain minimal annotation. Does not contain extensive analysis.

- CONTRACTOR REPORT. Scientific and technical findings by NASA-sponsored contractors and grantees.

- CONFERENCE PUBLICATION. Collected papers from scientific and technical conferences, symposia, seminars, or other meetings sponsored or cosponsored by NASA.

- SPECIAL PUBLICATION. Scientific, technical, or historical information from NASA programs, projects, and missions, often concerned with subjects having substantial public interest.

- TECHNICAL TRANSLATION. Englishlanguage translations of foreign scientific and technical material pertinent to NASA's mission.

Specialized services also include creating custom thesauri, building customized databases, organizing and publishing research results.

For more information about the NASA STI program, see the following:

- Access the NASA STI program home page at http://www.sti.nasa.gov

- E-mail your question via the Internet to help@ sti.nasa.gov

- Fax your question to the NASA STI Help Desk at 301-621-0134

- Telephone the NASA STI Help Desk at 301-621-0390

- Write to: NASA Center for AeroSpace Information (CASI) 7115 Standard Drive Hanover, MD 21076-1320 
NASA/TM-2008-215174

AIAA-2008-0439

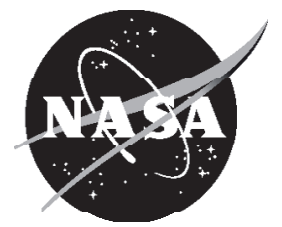

\section{Comparison of LEWICE and GlennICE in the SLD Regime}

William B. Wright

ASRC Aerospace Corporation, Cleveland, Ohio

Mark G. Potapczuk and Laurie H. Levinson

Glenn Research Center, Cleveland, Ohio

Prepared for the

46th Aerospace Sciences Meeting and Exhibit

sponsored by the American Institute of Aeronautics and Astronautics

Reno, Nevada, January 7-10, 2008

National Aeronautics and

Space Administration

Glenn Research Center

Cleveland, Ohio 44135 


\section{Acknowledgments}

The authors would like to acknowledge Colin Bidwell and Dean Miller from the NASA Glenn Research Center's Icing Branch as well as Paul Tsao and David Anderson from the Ohio Aerospace Institute for their insight and experience with SLD issues. We would also like to acknowledge Dr. Judith Van Zante and Tammy Langhals of ASRC Corporation for supplying the most recent SLD data in a timely manner for this report. The first author would also like to acknowledge the continued financial support from NASA Glenn for this research.

Trade names and trademarks are used in this report for identification only. Their usage does not constitute an official endorsement, either expressed or implied, by the National Aeronautics and Space Administration.

Level of Review: This material has been technically reviewed by technical management.

Available from

NASA Center for Aerospace Information 7115 Standard Drive

Hanover, MD 21076-1320
National Technical Information Service 5285 Port Royal Road Springfield, VA 22161 


\title{
Comparison of LEWICE and GlennICE in the SLD Regime
}

\author{
William B. Wright \\ ASRC Aerospace Corporation \\ Cleveland, Ohio 44135 \\ Mark G. Potapczuk and Laurie H. Levinson \\ National Aeronautics and Space Administration \\ Glenn Research Center \\ Cleveland, Ohio 44135
}

\begin{abstract}
A research project is underway at the NASA Glenn Research Center (GRC) to produce computer software that can accurately predict ice growth under any meteorological conditions for any aircraft surface. This report will present results from two different computer programs. The first program, LEWICE version 3.2.2, has been reported on previously. The second program is GlennICE version 0.1. An extensive comparison of the results in a quantifiable manner against the database of ice shapes that have been generated in the GRC Icing Research Tunnel (IRT) has also been performed, including additional data taken to extend the database in the Super-cooled Large Drop (SLD) regime. This paper will show the differences in ice shape between LEWICE 3.2.2, GlennICE and experimental data. This report will also provide a description of both programs. Comparisons are then made to recent additions to the SLD database and selected previous cases. Quantitative comparisons are shown for horn height, horn angle, icing limit, area and leading edge thickness. The results show that the predicted results for both programs are within the accuracy limits of the experimental data for the majority of cases.
\end{abstract}

\section{Introduction}

The Icing Branch at GRC has produced several computer codes (refs. 1 to 35) over the last twenty years for performing icing simulation. While some of these tools have been collaborative projects, most have been developed primarily by one person with some assistance by others. The state of computing has also changed dramatically in that time period. Early on, design decisions were made in these tools that took into consideration the limited capabilities of early computers. Additionally, the personnel tasked to design and write these computer codes were and remain icing experts, not software experts. As these codes have grown in complexity and have been accepted by users as production icing tools, there has arisen a need for the developers to adhere to standard software practices used to develop commercial software. The goals of these practices, as they relate to the GlennICE effort, include: creating a teambased development process rather than the current individual-based process; building modular code elements that can be re-used as needed by several processes; designing or redesigning code elements with future capabilities in mind; and developing efficient testing methodologies for testing and validation of the code. This report will, in part, provide an update on the status of that process and describe the current capabilities of the GlennICE software (refs. 36 and 37).

This report will address the validation of this software against a recent set of ice shape data in the Super-cooled Large Droplet (SLD) regime (ref. 38). This validation effort mirrors a similar effort undertaken previously for previous validations of LEWICE (refs. 39 and 40). Those reports quantified the ice accretion prediction capabilities of the LEWICE software. Several ice geometry features were proposed for comparing ice shapes in a quantitative manner. The resulting analysis showed that LEWICE compared well to the available experimental data.

The effects of super-cooled large droplets in icing have been researched extensively since the 1994 ATR-72 crash in Roselawn, Indiana (ref. 41). It has been speculated that the accident occurred due to the 
accumulation of ice aft of the deicing boots. This ice accumulation formed aft of the boots due to impingement of drops greater than $40 \mu \mathrm{m}$ in diameter. Since then, several experimental efforts have been made to document SLD ice shapes and to investigate the underlying physics (refs. 42 to 49). While this report will provide comparisons to standard icing conditions, the emphasis was placed on the newer data, which is predominately SLD.

The report is divided into four sections. The first section will provide a description of the LEWICE (ref. 34) software, the SmaggIce (ref. 35) software and the Naviér-Stokes flow solver WIND (ref. 50) that was used for this effort. The second section will provide a description of the GlennICE model with emphasis on the differences between the two development projects. The third section will describe the experimental data and the parameters used for quantifying the comparisons. The last section will provide validation results along with a statistical comparison of those parameters with the available experimental data.

\title{
Nomenclature
}

\author{
$B \quad$ ice height (m) \\ c chord (m) \\ $c_{n} \quad$ series term in analytic temperature solution $\left(\mathrm{m}^{-1}\right)$ \\ $c_{p} \quad$ specific heat $(\mathrm{J} / \mathrm{kgK})$ \\ $H \quad$ heat transfer coefficient $\left(\mathrm{W} / \mathrm{m}^{2} \mathrm{~K}\right)$ \\ $h \quad$ film thickness (m) \\ $k \quad$ thermal conductivity $(\mathrm{W} / \mathrm{mK})$ \\ $K_{L} \quad$ LEWICE splashing parameter (dimensionless) \\ $L \quad$ characteristic length (m) \\ $L W C \quad$ liquid water content $\left(\mathrm{g} / \mathrm{m}^{3}\right)$ \\ $\dot{m} \quad$ water mass flux $\left(\mathrm{kg} / \mathrm{m}^{2} \mathrm{~s}\right)$ \\ $n \quad$ unit normal (dimensionless) \\ $P \quad$ pressure $\left(\mathrm{N} / \mathrm{m}^{2}\right)$ \\ $Q \quad$ flow rate $\left(\mathrm{m}^{3} / \mathrm{s}\right)$ \\ $q$ heat flux $\left(\mathrm{W} / \mathrm{m}^{2}\right)$ \\ $s \quad$ surface wrap distance $(\mathrm{m})$ \\ $T$ temperature (K) \\ $t \quad$ time (s) \\ $V \quad$ velocity $(\mathrm{m} / \mathrm{s})$ \\ $W \quad$ impact velocity $(\mathrm{m} / \mathrm{s})$ \\ $w_{f} \quad$ wetness factor (dimensionless) \\ $x \quad$ chordwise direction $(\mathrm{m})$ \\ $Y \quad$ airfoil metal thickness (m) \\ $y \quad$ direction normal to the surface $(\mathrm{m})$
}

Dimensionless numbers:

$\mathrm{c}_{l} \quad$ skin friction coefficient $=\frac{2 \tau_{y=0}}{\rho_{\text {air }} V_{\infty}^{2}}$

$\mathrm{Nu} \quad$ Nusselt number $=\frac{H L}{k}$ 
Oh $\quad$ Ohnesorge number $=\frac{\mu}{\sqrt{\rho \sigma d}}$
$\operatorname{Pr} \quad$ Prandtl number $=\frac{c_{p} \mu}{k}$
$\operatorname{Re} \quad$ Reynolds number $=\frac{\rho V L}{\mu}$
St $\quad$ Stanton number $=\frac{H}{\rho_{\text {air }} c_{p} V_{\infty}}$

Greek letters:

$\alpha \quad$ thermal diffusivity ( $\mathrm{m} 2 / \mathrm{s})$

$\Lambda \quad$ latent heat $(\mathrm{J} / \mathrm{kg})$

$\mu \quad$ viscosity $(\mathrm{kg} / \mathrm{m} * \mathrm{~s})$

$v \quad$ kinematic viscosity of air $\left(\mathrm{m}^{2} / \mathrm{s}\right)$

$\rho$ density $\left(\mathrm{kg} / \mathrm{m}^{3}\right)$

Subscripts:

$\begin{array}{ll}a & \text { air } \\ \text { acc } & \text { accumulation } \\ \text { cond } & \text { conduction } \\ d & \text { drop } \\ e & \text { edge of boundary layer } \\ \text { eff } & \text { effective } \\ \text { evap } & \text { evaporation } \\ f & \text { freezing } \\ \text { film } & \text { film } \\ i & \text { ice } \\ i m p & \text { impinging } \\ k & \text { roughness } \\ m & \text { mass transfer } \\ m p & \text { melting point } \\ o & \text { total } \\ r b & \text { runback } \\ r e c & \text { recovery } \\ s & \text { surface } \\ s p l a s h & \text { splash } \\ t & \text { turbulent } \\ v & \text { vapor } \\ w & \text { water } \\ x & \text { x-dependent } \\ y & \text { y-dependent } \\ \infty & \text { free-stream property } \\ & \end{array}$




\section{Existing Computational Tools}

\section{LEWICE}

The computer program, LEWICE, embodies an analytical ice accretion model that evaluates the thermodynamics of the freezing process that occurs when super-cooled droplets impinge on a body. The atmospheric parameters of temperature, pressure, and velocity, and the meteorological parameters of liquid water content (LWC), droplet diameter, and relative humidity are specified. This information, along with the body geometry, is used to determine the shape of the ice accretion through an evaluation of the mass and energy balance associated with freezing of the incoming liquid water. The surface of the clean (un-iced) geometry is defined by segments joining a set of discrete body coordinates. The software consists of four major modules. They are: (1) the flow field calculation, (2) the particle trajectory and impingement calculation, (3) the thermodynamic and ice growth calculation, and (4) the modification of the current geometry by addition of the ice growth.

LEWICE applies a time-stepping procedure to "grow" the ice accretion. Initially, the flow field and droplet impingement characteristics are determined for the clean geometry. The ice growth rate on each segment defining the surface is then determined by applying the thermodynamic model. When a time increment is specified, this growth rate can be transformed into an ice thickness and the body coordinates are adjusted to account for the accreted ice. This procedure is repeated, beginning with the calculation of the flow field about the iced geometry, then continued until the desired icing time has been reached. The results shown in this report are from version 3.2.2 of LEWICE (ref. 34).

\section{WIND}

WIND-US (ref. 51) is an unstructured, multi-zone, compressible flow solver with flexible chemistry and turbulence models. Zonal interfaces may be abutting or overlapping, allowing the flexibility to treat complex systems moving relative to one another. WIND-US is a computational platform that may be used to numerically solve various sets of equations governing physical phenomena. Currently, the software supports the solution of the three-dimensional Euler and Naviér-Stokes equations of fluid mechanics, along with supporting equation sets governing turbulent and chemically reacting flows.

WIND-US is a product of the NPARC Alliance, a partnership between GRC and the Arnold Engineering Development Center (AEDC) dedicated to the establishment of a national, applicationsoriented flow simulation capability. The Boeing Company has also been closely associated with the Alliance since its inception, and represents the interests of the NPARC User's Association.

\section{SmaggIce}

The Surface Modeling and Grid Generation for Iced Airfoils (SmaggIce) (ref. 35) toolkit is a suite of interactive tools developed at GRC which can simplify and improve an icing effects study. This suite of tools is used to prepare two-dimensional cross sections of iced airfoils for computational fluid dynamics (CFD) analysis. SmaggIce is designed to help researchers and engineers study the effects of ice accretion on airfoil performance, which is difficult to do with other software packages because of the complexity of ice shapes (ref. 52). CFD tools are used primarily for certification studies and analysis, to evaluate safety of flight with unprotected surfaces and to determine the need for ice protection. In this study, SmaggIce was used to generate grids for each airfoil and for interim ice shapes in the multi-time step accretion process.

\section{GlennICE}

The GlennICE project was initiated in 1999 as a means to develop a consistent set of standards and practices for creation, use and maintenance of NASA administered icing computational tools. One goal of 
this process is to provide a mechanism for a more team-based approach to software development. Current development of icing codes at NASA has been more separated and individual-based. The plan has been to establish a common computational framework for integration of NASA icing analytical tools, and to create a set of requirements both for the development of these tools and for their integration into the common framework. The features of the resulting system would include providing a common user interface for all tools and allowing user selection of analysis modules. A modular design would allow more streamlined substitution of new or improved software elements, and the defined process would include documented standards for rapid integration of new software. This process also requires a version control system designed to allow both control of approved software and flexibility for rapid prototyping, as well as documentation that allows rapid identification of software design and use. The first step of this process has been to integrate existing icing computational tools and to redesign them if necessary so that they fit into the design. Where applicable, new or modified routines will be noted in this report. The following discussion will present each of the main subdivisions of the software and describe the modifications made.

\section{Grid Generation/Surface Geometry Modeling}

The methodology for generating surface points (panels if the potential flow solver is used) has been completely replaced. The current methodology relies on using the SmaggIce software described earlier in order to generate the surface points and grids (if needed) for 2D geometries. The philosophy in LEWICE was that the user should not have much control over the point distribution in order to provide uniformity of results when run by users with different experience levels. Using SmaggIce gives the user much more control over the point distribution and grids than could be done in LEWICE. Although SmaggIce is a GUI-driven interactive software, the program can be run with scripts that do not require user interaction. This allows both flexibility in point distribution and automation for multi-time step runs. Prior to the release of GlennICE, it will be necessary to test this feature in order to ensure that users with little or no experience can produce reliable results. The LEWICE routines for automatic point distribution may be added to GlennICE in the future based on feedback from the users. In 3D, grids are input in the same format as the LEWICE3D (ref. 32) code. The grid formats supported by LEWICE3D can also be used for 2D simulations. This feature allows the user additional flexibility in selecting a grid generator and flow solver since LEWICE3D supports a wide variety of formats. Automatic time stepping can only be used in this instance if the grid generator selected by the user can automatically produce accurate grids for the new geometry.

\section{Flow Solvers}

The potential flow solver in LEWICE was converted to Fortran90 so that it could be used in GlennICE. In addition, GlennICE can support both multi-block structured grids (max. 50 blocks) and unstructured grids. Additional integration with Naviér-Stokes solvers was performed to use more of the flow solution results in the heat transfer routines. In LEWICE, the user could have heat transfer coefficients (or heat fluxes) read from a file. It was presumed that the heat transfer coefficients were calculated in the Naviér-Stokes solver. Additionally, LEWICE would determine velocities at the edge of the boundary layer through use of Bernoulli's equation from the surface pressures. While this method gave heat transfer results very similar to potential flow, it did not use the Naviér-Stokes results to their fullest extent. In GlennICE, the heat transfer coefficient process was modularized so that the LEWICE heat transfer correlation could be used independently of the integral boundary layer. The LEWICE turbulent heat transfer correlation is taken from Schlichting (ref. 53) as 


$$
N u_{x}=\frac{\frac{1}{2} c_{f} \operatorname{Re}_{x} \operatorname{Pr}}{\operatorname{Pr}_{t}+\sqrt{\frac{1}{2} c_{f}} S t_{k}} \text { where } S t_{k}=0.52 \operatorname{Re}_{k}^{0.45} \operatorname{Pr}^{0.8}
$$

according to Owen and Thompson (ref. 54). This equation relies on the skin friction coefficient (available from the Naviér-Stokes solver), the local Reynolds number and the roughness Reynolds number. Of these three values, only the roughness Reynolds number is not output by Naviér-Stokes codes. The roughness Reynolds number can be calculated from the roughness height and the velocity at the roughness height estimated from the Naviér-Stokes solution. In order to complete the analysis, the laminar heat transfer coefficient and transition location are needed as well. The laminar heat transfer coefficient is simply related to the local Reynolds number by

$$
N u=\frac{1}{3} \operatorname{Pr}^{1 / 3} \operatorname{Re}_{x}^{1 / 2}
$$

Transition is determined when the roughness Reynolds number is greater than 600 . This differs slightly from the value LEWICE uses. LEWICE varies the transition criteria based on distance from the stagnation point. Thus far, this was not implemented into the Naviér Stokes interface in order to avoid having to determine a single stagnation point for complex flows. Separating the heat transfer correlations from the boundary layer routine allows the Nusselt number to be determined as a point calculation rather than integrating from a starting location. This change implicitly assumes that the flow can transition back to laminar if the roughness Reynolds number drops below 600 at any location. This change also modularizes each step along the process so that developers can change each equation independently. This will allow alternate heat transfer correlations to be easily implemented if improvements to this model are determined experimentally.

In addition, GlennICE can use momentum thickness rather than skin friction by using the following expression for shear stress:

$$
\tau=\frac{0.1682 \rho V_{\infty}^{2}}{\left(\log \left(864 \frac{\theta_{t}}{x_{k}}+2.568\right)\right)^{2}} ; c_{f}=\frac{2 \tau}{\rho V^{2}}
$$

\section{Collection Efficiency/Water Mass Flux}

GlennICE uses the same routines as LEWICE and LEWICE3D for determining collection efficiency by integrating individual particle trajectories. In addition, the LEWICE collection efficiency module was converted to Fortran90 and modularized. This will allow other routines to more easily access the SLD models in LEWICE for splashing, bouncing, breakup and reimpingement. Those routines were modified such that they are useable in either 2D or 3D. In their current form, developers can also change the individual SLD effects by only changing a single routine. In addition, the interpolation routines for air velocity were modified to accommodate unstructured grids. A higher accuracy interpolation scheme was implemented that matches derivatives at grid boundaries (ref. 55). GlennICE uses the following models in the SLD regime: 


\section{Breakup}

If $W e_{d}=\frac{\rho_{a} V_{d}^{2} d}{\sigma}>13$, then the drop instantaneously breaks up into smaller particles that have the same velocity and direction as the original drop. The new drop size is given by

$$
d_{\text {new }}=6.2 d_{\text {old }}\left(\frac{\rho_{w}}{\rho_{a}}\right)^{1 / 4} \operatorname{Re}_{w}^{-1 / 2}
$$

\section{Splashing/Bouncing}

If $K_{L}=\frac{0.859 \sqrt{O h_{w} \operatorname{Re}_{w}{ }^{1.25}}\left(\frac{\rho_{w}}{L W C}\right)^{0.125}}{\left(\sin \alpha_{i m p}\right)^{1.25}}>200$, then the fraction mass loss is determined by the following equation

$$
\frac{m_{\text {loss }}}{m_{\text {imp }}}=0.7\left(1-\sin \alpha_{\text {imp }}\right)\left(1-\exp \left(-0.0092026\left(K_{L}-200\right)\right)\right)
$$

The sizes of the splashed particles are given by $d_{\text {splash }}=8.72 d_{\text {imp }} e^{-0.0281 K}$ where $K=O h_{w} \operatorname{Re}_{w}^{1.25}$.

The velocity and direction of the splashed particles are given by $V_{x, \text { splash }}=V_{x, \text { imp }}\left(1.075-0.0025 \alpha_{\text {imp }}\right)$, $V_{y, \text { splash }}=V_{y, \text { imp }}\left(0.3-0.002 \alpha_{\text {imp }}\right)$ and $\alpha_{\text {splash }}=\tan ^{-1}\left(\frac{V_{y, \text { splash }}}{V_{x, \text { splash }}}\right)$. A single splashed particle is then tracked using the same Lagrangian particle tracking schemes used to determine the initial impact. If the particle reimpinges, the splashed mass is added to the new location.

\section{Ice Density}

For any cell that is rime $\left(N_{f r}=1\right)$, the ice density in SLD is given by $\rho_{i}=917 \mathrm{~kg} / \mathrm{m}^{3}$ for $M V D<40 \mu \mathrm{m}$ $\rho_{i}=917-1.5(M V D-40)$ for $40 \mu \mathrm{m} \leq M V D \leq 318 \mu \mathrm{m}$ and $\rho_{i}=500 \mathrm{~kg} / \mathrm{m}^{3}$ for $M V D>318 \mu \mathrm{m}$. The splashed mass loss and density changes were both determined empirically from previous data (refs. 49 and 84 to 87). For GlennICE, the ice density correlation is used for both rime and glaze ice shapes. Since the correlation defaults to a constant value for $M V D<40 \mu \mathrm{m}$, it is used for both SLD $=1$ and SLD $=0$ options in the LEWICE and GlennICE input files.

\section{Energy Balance}

The energy balance equations were re-derived and implemented from scratch in modular form for GlennICE. A review of other sources (refs. 56 to 63) determined that there were two differences in the formulations used by LEWICE and by other icing codes. The first difference was in the evaporation model. While the mass lost by evaporation is very small for an unheated analysis, the energy term can be quite substantial since the heat of vaporization is much larger than the heat of fusion. All of the formulations use the Chilton-Colburn approximation to tie the mass transfer coefficient to the heat transfer coefficient. However there is a slight difference in the implementation of the concentration difference. Messinger uses the following equation 


$$
q_{\text {evap }}=\Lambda_{v} h_{m} \frac{\frac{P_{v}\left(T_{s}\right)}{T_{s}}-\frac{P_{o}}{T_{o}} \frac{P_{v}\left(T_{e}\right)}{P}}{\frac{1}{0.622} \frac{P_{o}}{T_{o}}-\frac{P_{v}\left(T_{s}\right)}{T_{s}}}
$$

This equation has also been used for scaling conditions (ref. 64) for icing tunnel tests and by Gent (ref. 57) in the TRAJICE code after accounting for compressibility effects. LEWICE uses a simplified form of this equation by noting that the second term in the denominator is very small for unheated surfaces, giving

$$
q_{\text {evap }}=\Lambda_{v} h_{m} \frac{\frac{P_{v}\left(T_{s}\right)}{T_{s}}-\frac{P_{o}}{T_{o}} \frac{P_{v}\left(T_{e}\right)}{P}}{\frac{1}{0.622} \frac{P_{o}}{T_{o}}}
$$

Myers (ref. 60) and Bourgault (ref. 62) linearize the above equation for easier solution by matrix solvers even though the vapor pressure term is highly non-linear. The approximation was justified by noting that the surface temperature is usually near freezing even for rime conditions. The vapor pressure in LEWICE was derived from a curve-fit of tabulated data and is given as

$$
\ln \left(P_{v}\right)=20.15247167-\frac{11097.16963}{1.8 T}
$$

An alternate expression is given by the Goff-Gratch equation (ref. 65) for supercooled water

$$
\begin{aligned}
& \log _{10}\left(P_{v}\right)=-7.90298\left(\frac{373.16}{T}-1\right)+5.02808 \log _{10}\left(\frac{373.16}{T}\right)-1.3816^{*} * 10^{-7}\left(10^{11.344(1-T / 373.16)}-1\right) \\
& +8.1328 * 10^{-3}\left(10^{-3.49149(373.16 / T-1)}-1\right)+\log _{10}(1013.246)
\end{aligned}
$$

The Goff-Gratch equation gives slightly higher values at low temperatures. Each of these methods has been implemented into GlennICE for evaluation. GlennICE comparisons shown in this report will use the formulation in LEWICE.

The second term that differs in the energy balance is the treatment of the heat lost into an unheated surface due to conduction. Messinger ignored this effect. LEWICE assumes an analytical formulation based on treating the airfoil as a semi-infinite surface. This gives the conduction loss as

$$
q_{\text {cond }}=\frac{2 k_{a}\left(T_{r e c}-T_{m p}\right)}{\sqrt{\pi \alpha_{a}}} \frac{\left(\sqrt{t_{2}}-\sqrt{t_{1}}\right)}{t_{2}-t_{1}}
$$

LEWICE can also directly calculate the heat loss due to conduction by using the thermal deicer option and turning off all the heat generation. This is an acceptable option to use when interfacing with a Naviér-Stokes solver, but adds significant computational time otherwise. The direct calculation of heat conduction losses is also performed by Myers in the ICECREMO code and by Bourgault in FENSAPICE. Myers also provides an approximate expression by assuming that no heat is actually lost into the airfoil, resulting in a pseudo-steady state heat flux 


$$
q_{\text {cond }}=k_{a} \frac{T_{s}-T_{m p}}{B}
$$

where $B$ is the ice height, which changes with time and $T_{s}$ is the airfoil surface temperature, which is assumed not to change. A third approximation can be obtained by solving the heat conduction equations analytically using more appropriate boundary conditions. In this formulation, it is assumed that the inner surface of the airfoil has an adiabatic boundary condition and that conduction occurs normal to the surface. Using a standard separation of variables solution arrives at the following infinite series

$$
\frac{T_{m p}-T}{T_{m p}-T_{\text {rec }}}=\sum_{n=0}^{\infty} 2 e^{-\alpha_{a} c_{n}{ }^{2} t} \frac{\sin \left(c_{n}\right)}{c_{n}} \cos \left(c_{n} \frac{y}{Y}\right) \text { with the eigenvalues being given by } c_{n} \tan \left(c_{n}\right)=\frac{k_{i} Y}{k_{a} B}
$$

The heat flux at the surface is then

$$
q_{\text {cond }}=\frac{2 k_{a}\left(T_{r e c}-T_{m p}\right)}{Y} \sum_{n=0}^{\infty} e^{-\alpha_{a} c_{n}{ }^{2} t} \sin ^{2}\left(c_{n}\right)
$$

The first three terms of the series, as well as the Myers conduction expression, have been incorporated as an alternate expression for the conduction heat loss.

\section{Mass Balance}

Myers (ref. 61) provides the following expression for the surface mass balance and film flow:

$$
\rho_{w} \frac{\partial h}{\partial t}+\rho_{w} \nabla \cdot Q=-\rho_{i} \frac{\partial B}{\partial t}-\rho_{w} W \cdot n
$$

In this expression, $W$ represents the net velocity of water impinging (impingement - evaporation) and $Q$ represents the combined effects of pressure, gravity and shear stress. The terms in this expression have the following physical meaning

$\rho_{w} \frac{\partial h}{\partial t}=$ rate of accumulation

$\rho_{w} \nabla \cdot Q=$ net rate of water transport

$\rho_{i} \frac{\partial B}{\partial t}=$ rate of ice accumulation

$-\rho_{w} W \cdot n=$ rate of impingement - rate of evaporation

However, using the nomenclature used in LEWICE for these terms, this expression becomes

$$
\dot{m}_{a c c}+\dot{m}_{r b}=\dot{m}_{i}-\dot{m}_{f r}-\dot{m}_{e}
$$


which is the equivalent expression used in LEWICE for the mass balance. The difference between the two formulations resides in the value of film height, not in the actual mass balance. LEWICE also uses the approximation that film accumulation and runback do not occur simultaneously, hence

$$
\rho_{w} \frac{\partial h}{\partial t}=-\rho_{i} \frac{\partial B}{\partial t}-\rho_{w} W \cdot n \text { for } t<t_{s}
$$

and

$$
\rho_{w} \nabla \cdot Q=-\rho_{i} \frac{\partial B}{\partial t}-\rho_{w} W \cdot n \text { for } \mathrm{t}>\mathrm{t}_{\mathrm{s}}
$$

where $t_{s}$ is the time needed to reach steady state. The time to reach steady state is determined from the approximation for steady film height, hence

$$
t_{s s}=\frac{h_{s s}}{\beta_{\max } V_{\infty}} ; \text { where LEWICE uses } h_{s s}=\left(\frac{\sigma}{\rho_{w}}\left[\frac{2}{w_{f}\left(\frac{d V}{d s}\right)_{\text {stag }}}\right]^{2}\right]^{1 / 3}
$$

and

$$
\text { Myers gives } h_{s s}=5 * 10^{-6}+0.40655 \sqrt{\frac{\mu_{w} \dot{m}_{i n}}{\rho_{w} \tau}}
$$

The mass balance attributed to Messinger ignored the film accumulation effect and used only the steady-state approximation. The mass balance in GlennICE has been formulated such that film accumulation and film transport (runback) can occur simultaneously although the Myers formulation has not yet been added as an option. There is an additional change that needs to be made to the process for GlennICE. In LEWICE, since the ice accretion is 2D (LEWICE3D uses a 2D strip approach for ice accretion as well) an explicit marching scheme can be used as the solution mechanism for water film. The solution starts at the stagnation point and marches outward from that point. This solution mechanism is still valid for 2D flows, provided there is no water film transport into a region where the airflow is separated. However, in order to accommodate a full 3D ice accretion process, an alternative solution mechanism is needed. The current scheme uses Gauss-Seidel iteration to solve for the water flux. In addition, this solution mechanism can also be used for 2D or 2D strip solutions. While the iterative solution is slower than the explicit marching scheme in $2 \mathrm{D}$, they provide identical results. The modular form of the current scheme was designed to allow for coupling with alternate water flow schemes (refs. 66 and 67). Each of these alternative approaches have been added to GlennICE. Due to the large number of cases that need to be ran for validation, only the current LEWICE model has been assessed for this report.

\section{Ice Growth}

Once the amount of ice to be added has been determined, the ice volume (or area in 2D) can be added to the existing geometry. LEWICE has the capability of growing ice normal to the surface, normal to the impacting particle and normal to the flow angle (angle of attack). The latter two options are internal to LEWICE and cannot be user-selected. In addition, LEWICE adds or removes points to the surface as 
needed in order to produce smoother ice shapes. GlennICE can use the LEWICE growth methodology for 2D geometries, however 3D growth is much more complex. Currently, 3D ice growth can only be performed using the three growth direction models mentioned above. The scheme for adding or removing points to the surface can only be used in 2D. In addition, SmaggIce can only be used on 2D geometries and grids must be read in from external files. For these reasons, ice accretion in 3D can only be performed in a single time step.

\section{Experimental Data}

The experimental data described in this paper are the result of a wide variety of tests performed in the NASA Glenn Icing Research Tunnel (IRT) in recent years (refs. 38 and 68 to 87). An emphasis was placed on recent additions to the SLD database that had not been compared with LEWICE. Eight airfoils were selected for this comparison as shown in figure 1. These airfoils and the accompanying ice shapes represent the complete set of publicly available data that has been generated in the IRT and digitized for single element airfoils. There is some data available on multi-element airfoils, but it was considered to be an insufficient amount for validation purposes. There are a total of 1200 IRT runs analyzed for this validation report, of which 507 are repeats of previous runs in the IRT. There are 1326 digitized tracings at off-centerline locations for a total of 3033 experimental ice shapes. The seven airfoils are as follows: a modified NACA 23014, a Large Transport Horizontal Stabilizer (LTHS), a GLC 305 business jet airfoil, a second business jet wing, a NACA 0012, a modified NACA 4415, a NACA 0015, and a NLF 0414
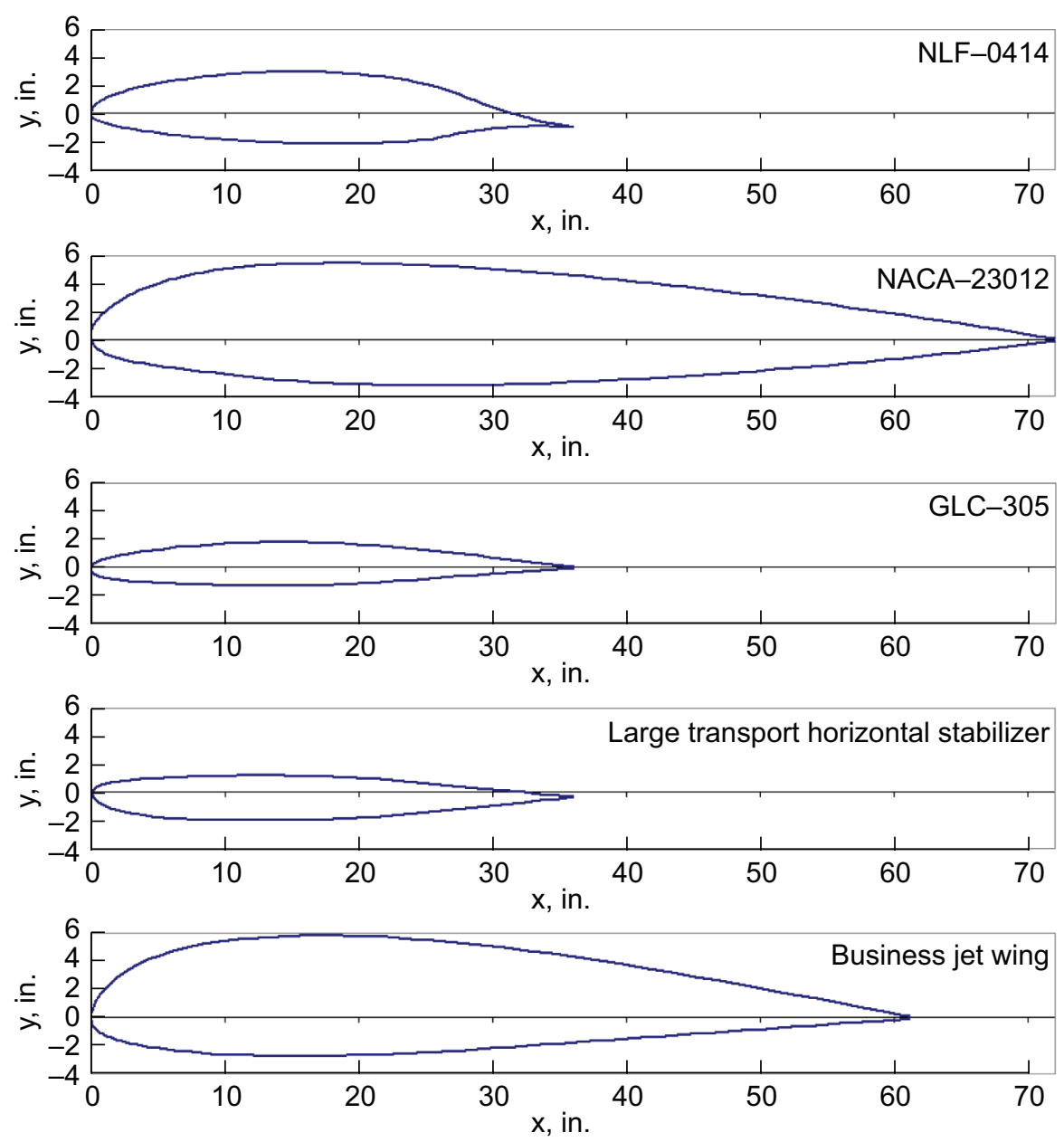

Figure 1.-Airfoils used in SLD validation. 
laminar flow general aviation wing. Many of these models were described in an earlier report on the LEWICE 2.0 validation effort. In addition to this data set, a newer database has been developed consisting almost exclusively of SLD ice shapes (ref. 38).

The data is taken in the IRT by cutting out a small section of the ice growth down to the airfoil and tracing the contour of the ice shape onto a cardboard template with a pencil. The pencil tracing is then transformed into digital coordinates with a hand-held digitizer. A flatbed scanner with digitizing software has been available to accelerate the data acquisition process. For any given IRT test run, up to five spanwise sections of the ice shape are traced and digitized in this manner. There are several steps within this process that can potentially cause experimental error. Those that can be quantified by the current technique are the spanwise variability, the repeatability error, and errors involved in the tracing technique.

\section{Results and Comparison Methodology}

This section describes the methodology used to make the quantitative measurements on experimental and predicted ice shapes. This methodology has been incorporated into a software utility called THICK that calculates and outputs the parameters described. This software was created in order to process the large number of ice shapes presented in this report. This program reads two geometry files: one for the clean airfoil and one containing an ice shape. This utility has been documented more thoroughly in the LEWICE 3.0 User Manual (ref. 29). This software has recently been revised to more accurately capture ice features of interest. An additional output file called "ReducedPeaks.dat" provides the location of other ice features that may or may not be ice horns that can be evaluated by the user. This file replaces the output "Peaks.dat" which often had too many peaks for a user to manually consider when applied to experimental ice shapes. The ice shapes are categorized using icing limit, area, horn height, horn thickness and leading edge thickness. The parameters were defined in the previous validation report, although area is now defined as the true area rather than the integrated thickness.

The previous section which describes the GlennICE software centered on alternatives to the LEWICE model for several features. A comprehensive validation of the software would require validation of each feature and combination of features. Time constraints prohibited a comprehensive comparison of this type. Instead, validation for the moment will be limited to the GlennICE routines that model the same physics used in LEWICE. This limitation results in an exact match for all ice shapes where $M V D \leq 40 \mu \mathrm{m}$. The modified ice density correlation becomes the only routine that differentiated the two programs. This level of agreement between the two software programs was intentional. In order to show that a change in a physical model has an effect on ice shape, it was necessary to first have the ability to recreate LEWICE results in the new framework. Because of this, results for $M V D \leq 40 \mu \mathrm{m}$ will not be shown as those results were reported on previously (ref. 34). In addition, whereas the discussion below may attribute results to LEWICE or GlennICE, the outputs are the same once the density model to LEWICE has been modified. Therefore these results are more accurately attributable to LEWICE 3.3 or GlennICE 0.1. There are 177 SLD cases to consider in the new database of which 12 are sequential spray cases designed to simulate bimodal drop distributions typical of freezing drizzle conditions. In addition, there are 521 SLD cases on NACA0012 airfoils from the previous validation of which 132 are sequential sprays.

The comparison methodology will follow previous LEWICE validation efforts (refs. 39 and 40). Measured values are the lower and upper icing limit, area, leading edge minimum thickness, lower and upper horn thicknesses and lower and upper ice horns. The report on the SLD database (ref. 38) provided results for ice height and horn angles. The other parameters (icing limit, area, leading edge minimum) were determined by using the THICK utility. The comparison for icing limit is shown in figure 2 . This figure shows a significant decrease in accuracy for predicting icing limit for SLD cases. While some of this difference can be attributed to the difficulty in measuring icing limit experimentally, this factor alone cannot fully explain the difference. Much of the difference on the lower icing limit can be attributed to the use of a monodispersed drop size as shown by the decrease in the error for the lower icing limit. This occurs because the monodisperse $M V D$ results underpredict the icing limit for 75 percent of the SLD 


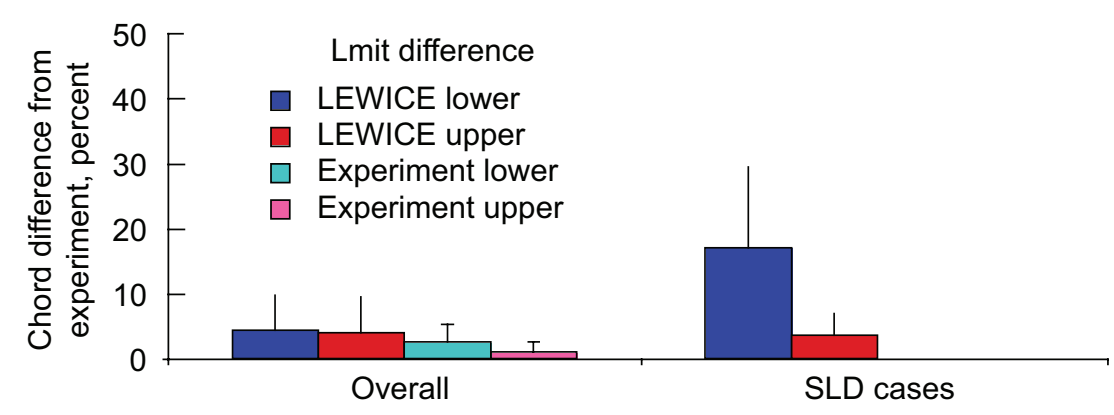

Figure 2.--Icing limit comparison

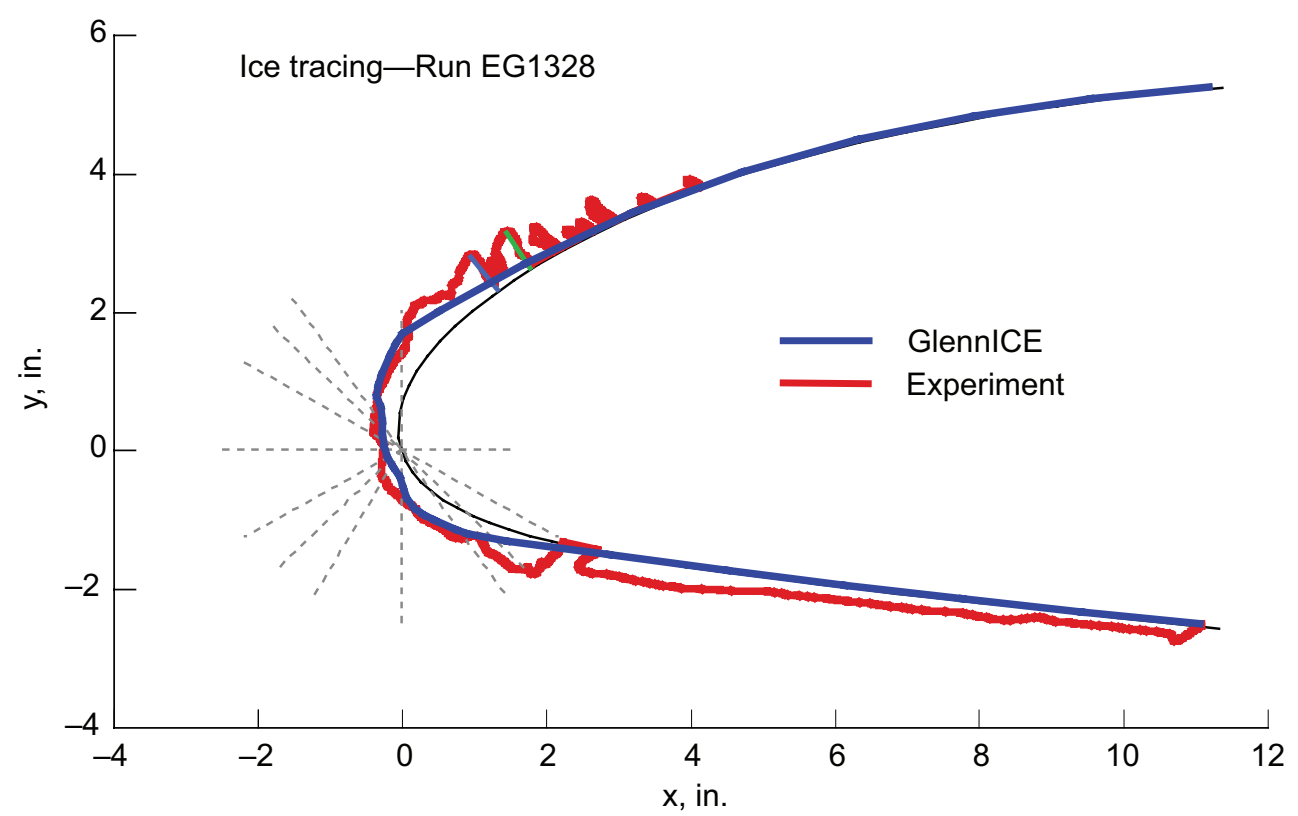

Figure 3.-Experimental ice shape with extended icing limit.

cases. However, use of an 11-bin drop size distribution for these cases resulted in a significant over prediction for the icing limit. Therefore, it may be necessary to combine a bouncing model that reduces impingement limit with the drop size distribution cases to more accurately predict the icing limits. The current model just reduces the mass in the downstream region but does not change the icing limit. The upper icing limit had an equal number of cases under predicted and over predicted. The differences between the code results and experiment are not simply limited to the measured difference in icing limit. The experimental ice shapes often have large feathers downstream of the leading edge whereas the code results tend to have icing limits that taper off to zero. Figure 3 shows an example of this type of shape. LEWICE (and GlennICE) predict the ice shape well past the start of the feather formation, but the threedimensional nature of the SLD feathers is not modeled in either code. Figures 4 and 5 show photographs of the lower and upper surface respectively. These figures show that the ice feathers are separated and do not form a solid ridge, which is the effect imagined when looking at the two-dimensional tracing.

Figure 6 shows the comparison for the Leading Edge Minimum Thickness and Ice Area. The ice area is actually much better predicted in the SLD regime than for standard drop sizes. This agreement is rather fortuitous however. As shown in figure 4, the experimental ice shape in the feather region is largely threedimensional. The tracings, however, are two-dimensional and individual feathers are often not traced. A standard experimental technique is used where the pencil is traced over the top of individual feathers where it cannot reach to the bottom of each individual feather. This results in the traced experimental ice 


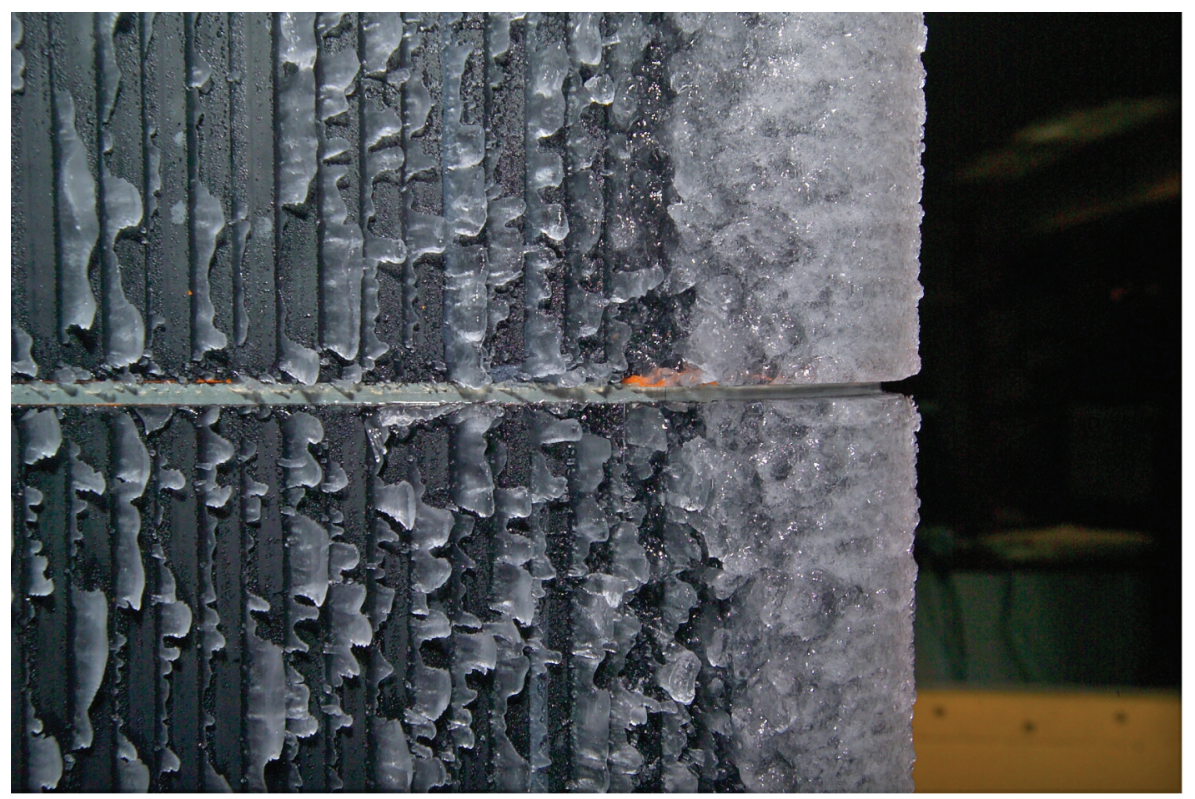

Figure 4.-Photograph of lower surface ice for case EG1328.

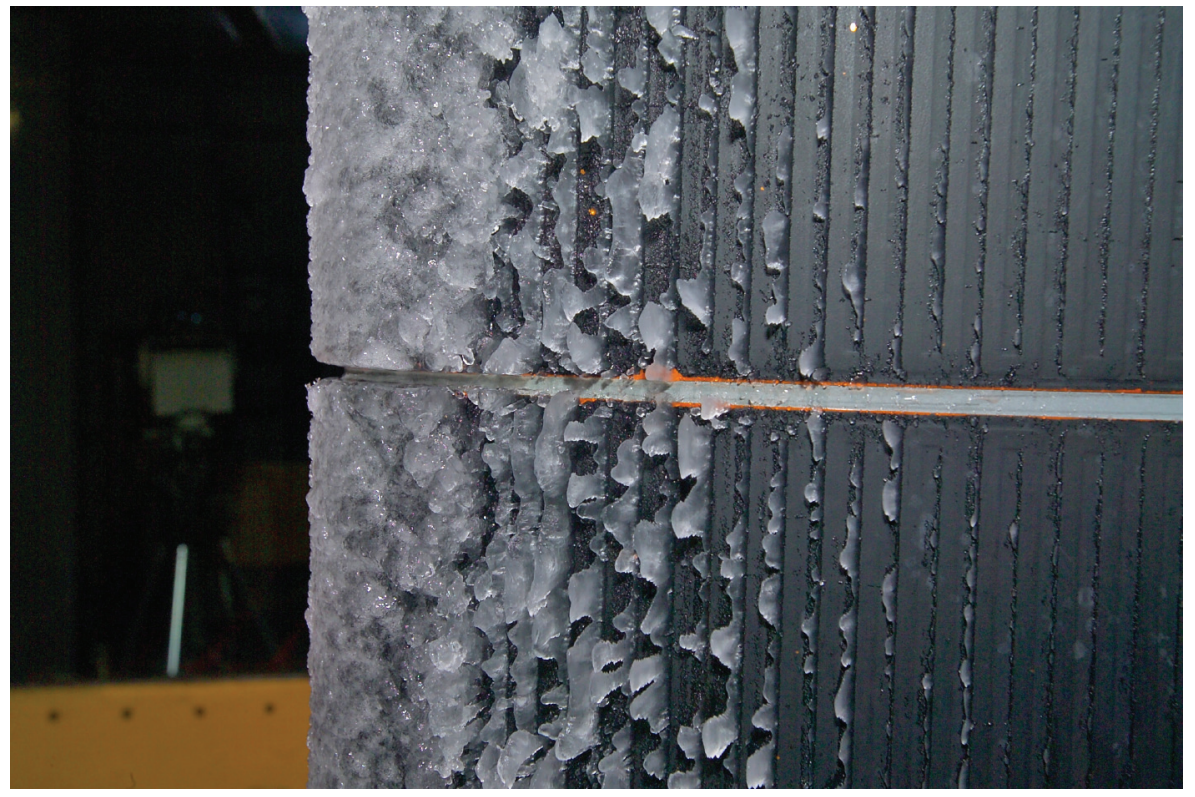

Figure 5.-Photograph of upper surface ice for case EG1328.

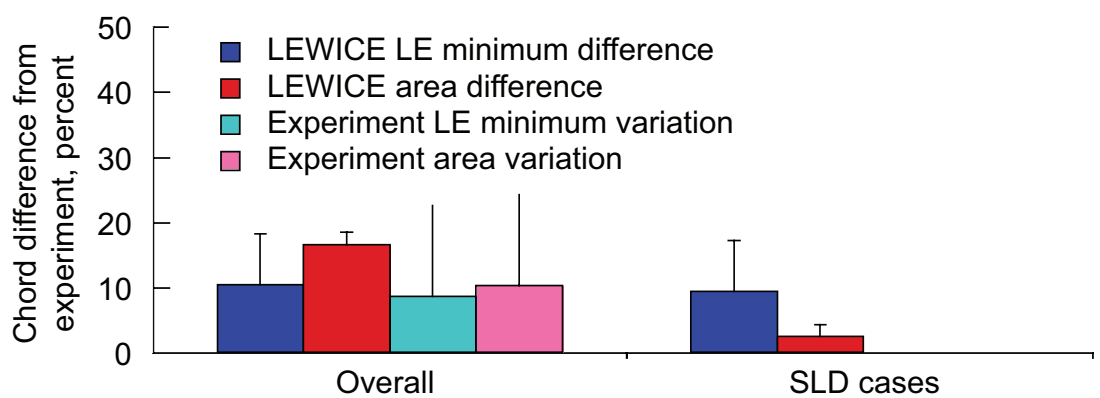

Figure 6.-Ice area and LE minimum. 


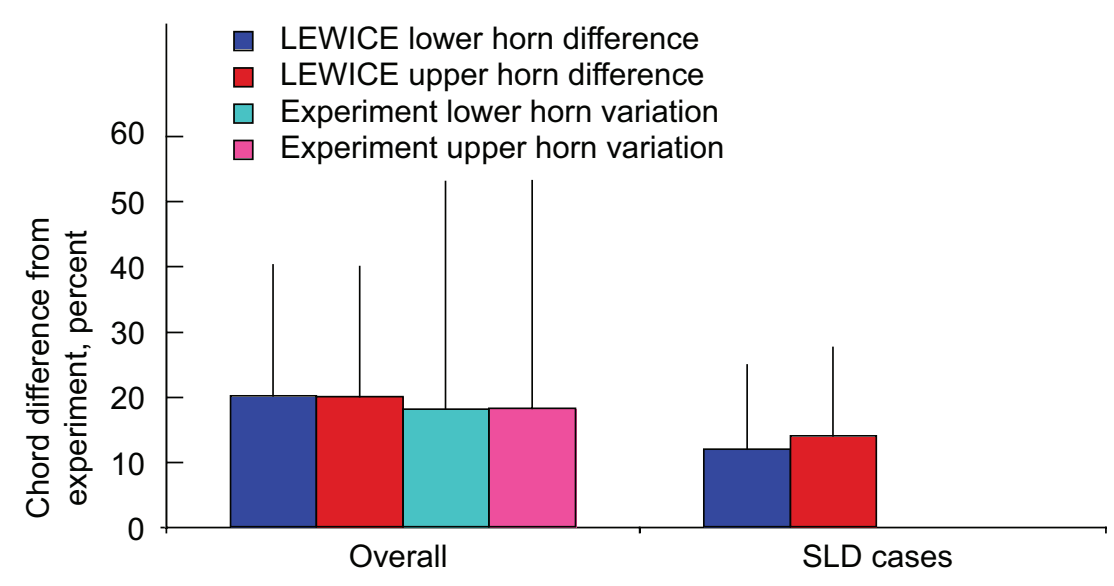

Figure 7.-Lower and upper horn height.

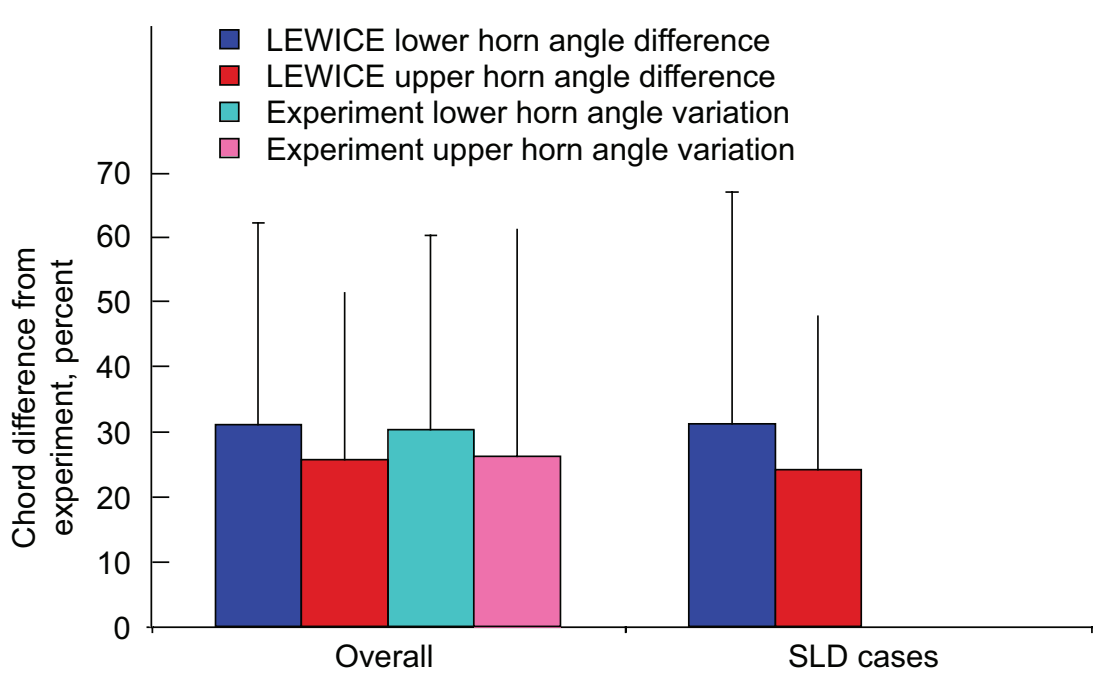

Figure 8.-Lower and upper horn angle.

shape appearing larger than it actually is in the photograph. It can be safely concluded that the codes over predict the ice area but the tracing process covers up this result.

Figure 7 shows the comparison for the lower and upper ice horns while figure 8 shows the comparison for lower and upper horn angle. The comparison of SLD shapes to experiment shows approximately the same difference as for standard ice shapes. For the experimental ice shapes, the upper and lower horns were selected manually rather than allowing THICK to automatically select the largest feature. This process was used due to the high variability of the experimental ice shapes. THICK often has trouble locating the correct horn locations without manual intervention. Running THICK automatically on each shape produced the code values for horn thickness and horn angle. This was done to save time in the analysis and was justified on the basis that the code results are smoother and an automated process could be used. However, it is possible that THICK did not select the correct horn locations for all cases. Figures 9 and 10 show examples of cases with large variations in the upper horn location. This result occurs because upper surface feather features were selected for the experimental "horn" location whereas the code predicts only the main ice shape and does not model the feather ice process. This resulted in a $128^{\circ}$ difference in the tabulated measurement for the lower horn angle in the first case and a $117^{\circ}$ difference in the upper horn angle in the second case. Neither result is reflective of the general agreement between the experimental ice shape and the code results. Figures 11 and 12 show 


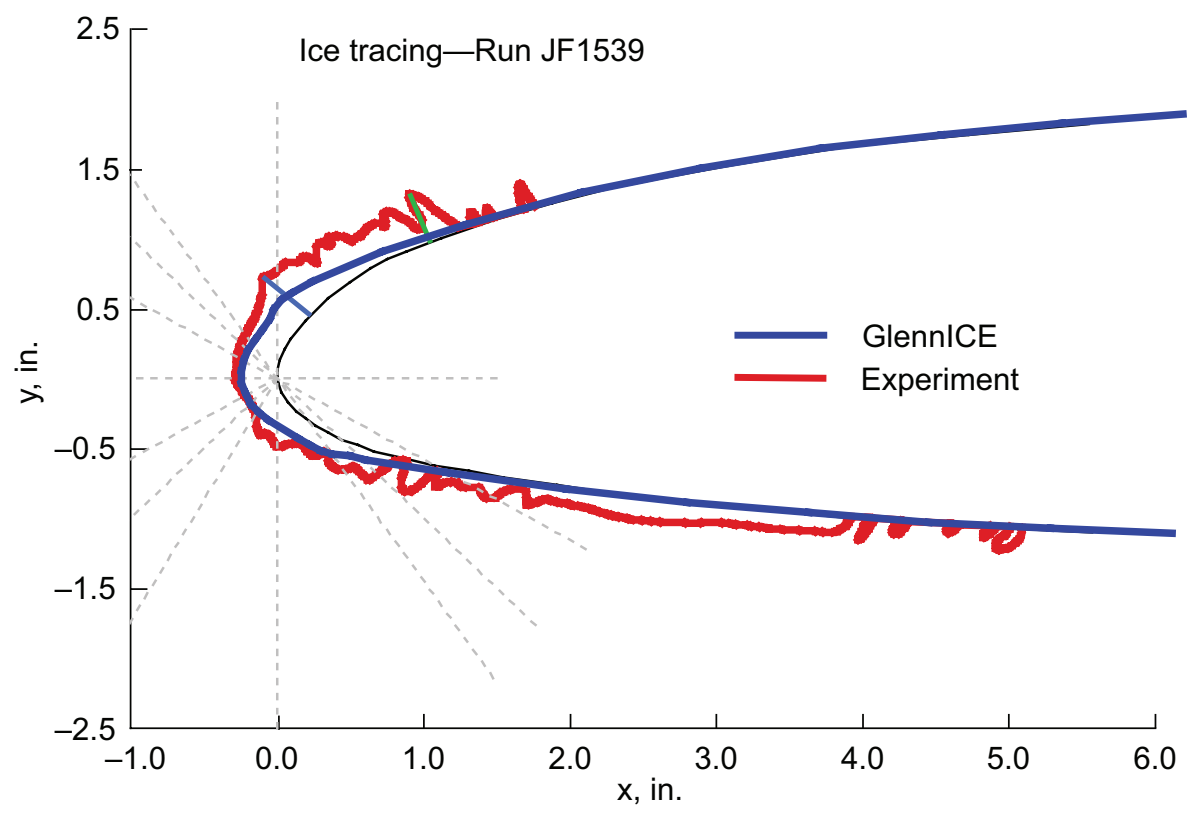

Figure 9.-Example ice shape with large horn angle difference.

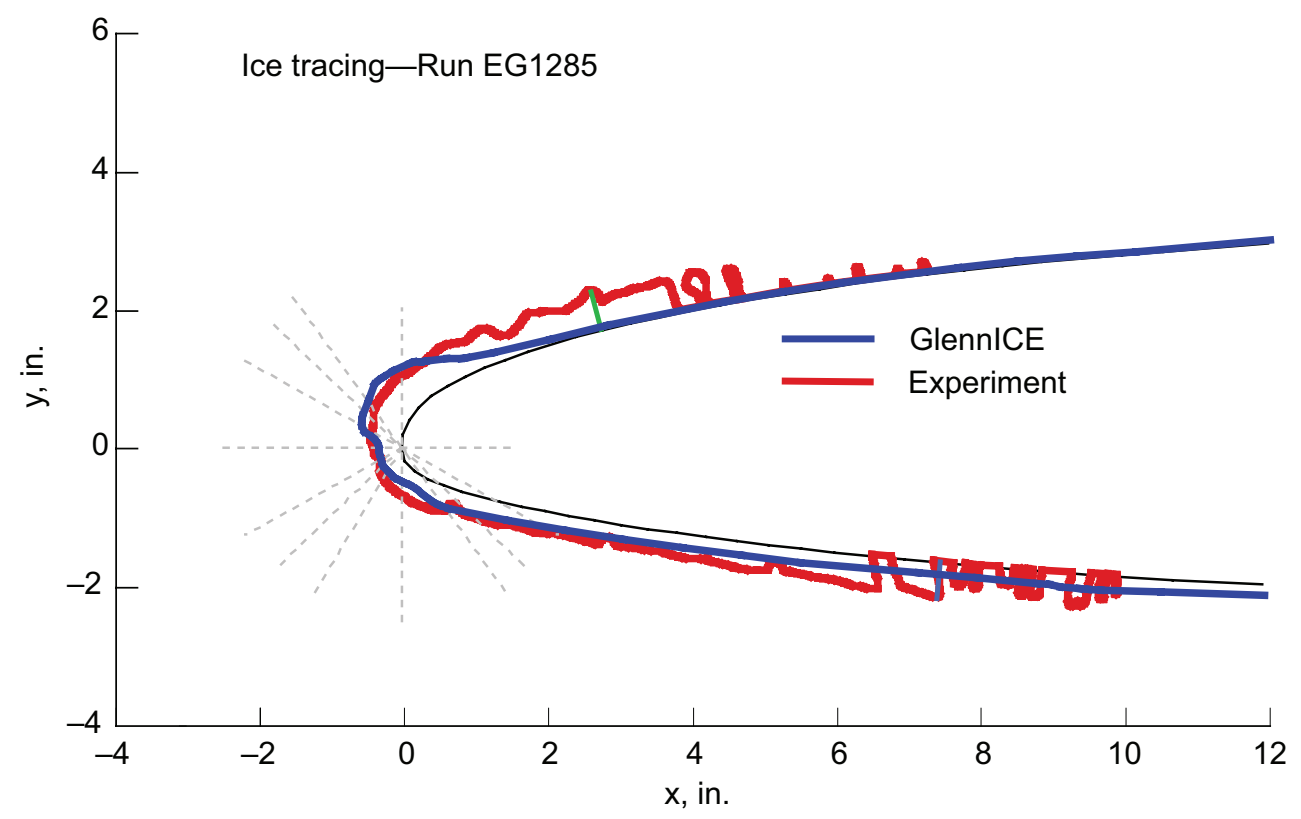

Figure 10.-Example ice shape with large horn angle difference.

the photographs of the ice shape for these two shapes. In both cases, there are several prominent ice features that could be selected as the horn location other than the one selected.

Figure 13 shows the ice shape that has the best comparison by the quantitative comparison methodology. The ice shape comes from a NACA23012 airfoil with the following conditions: $c=72$ in., $V=200 \mathrm{kts}, \alpha=2^{\circ}, T_{o}=-10^{\circ} \mathrm{F}, M V D=225 \mu \mathrm{m}, L W C=0.55 \mathrm{~g} / \mathrm{m}^{3}, t=10 \mathrm{~min}$. This case shows that even for a very high water loading, the codes can produce ice shapes that are representative of the experimental data. The average comparison is shown in figure 14. The conditions for this case are $c=36$ in., $V=$ $250 \mathrm{kts}, \alpha=2^{\circ}, T_{o}=-10^{\circ} \mathrm{F}, M V D=156 \mu \mathrm{m}, L W C=0.30 \mathrm{~g} / \mathrm{m}^{3}, t=10 \mathrm{~min}$. The horns on the 


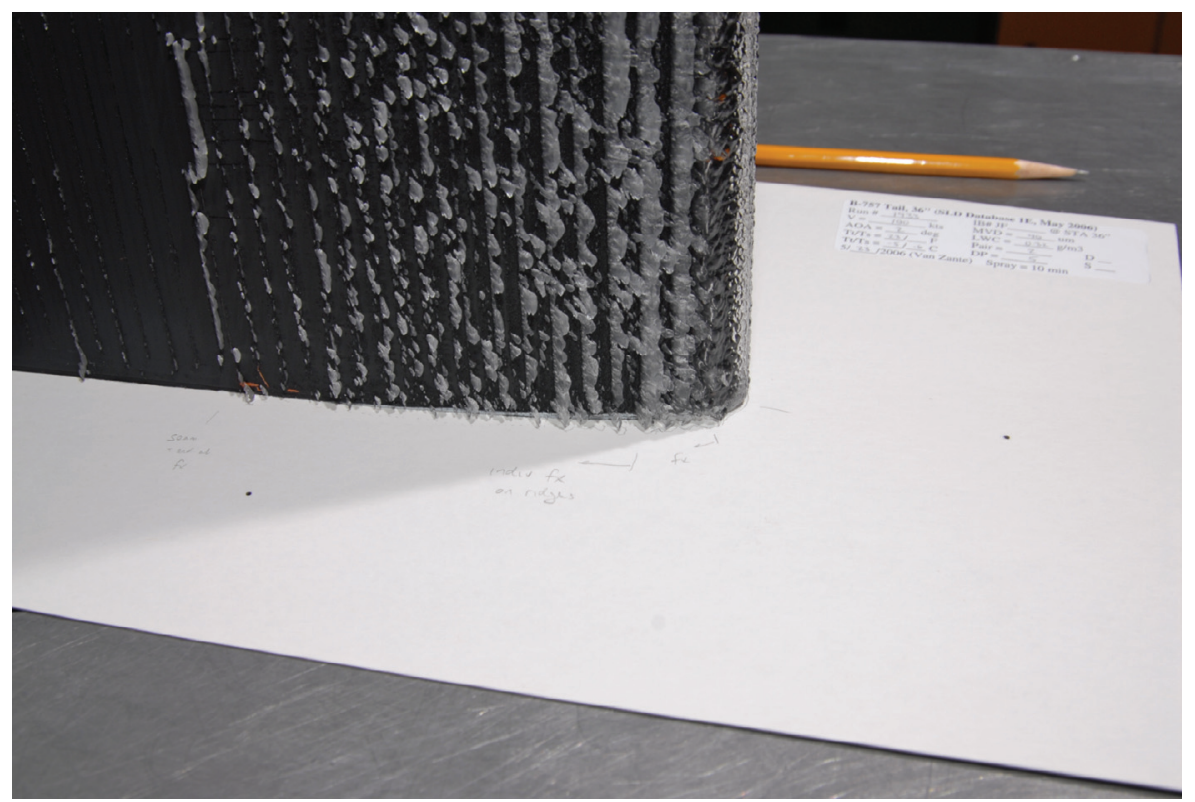

Figure 11._Photograph of lower surface ice for case JF1539.

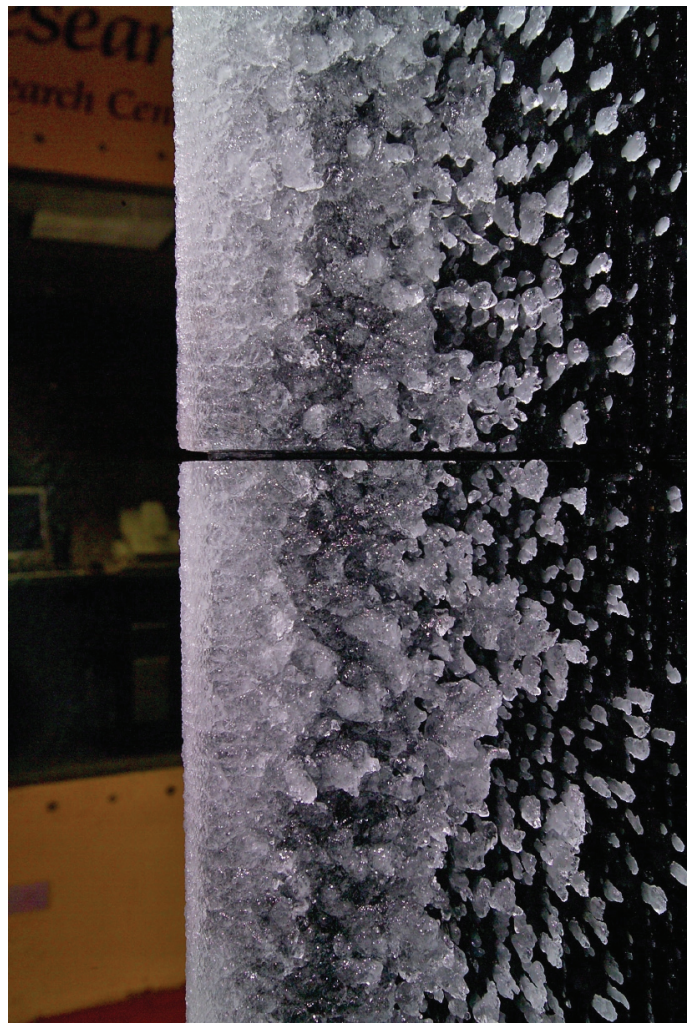

Figure 12.-Photograph of upper surface ice for case IF1285. 


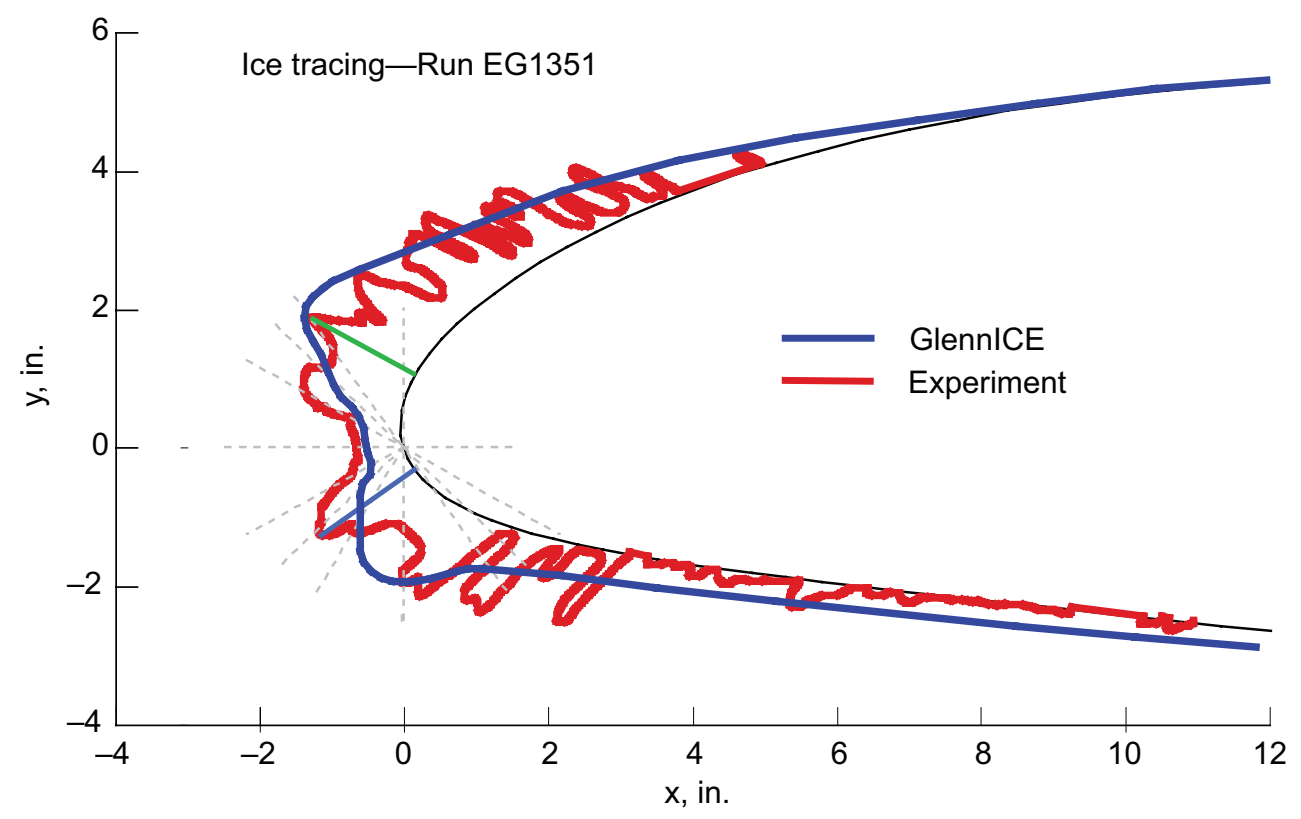

Figure 13.-Best comparison from measured parameters.

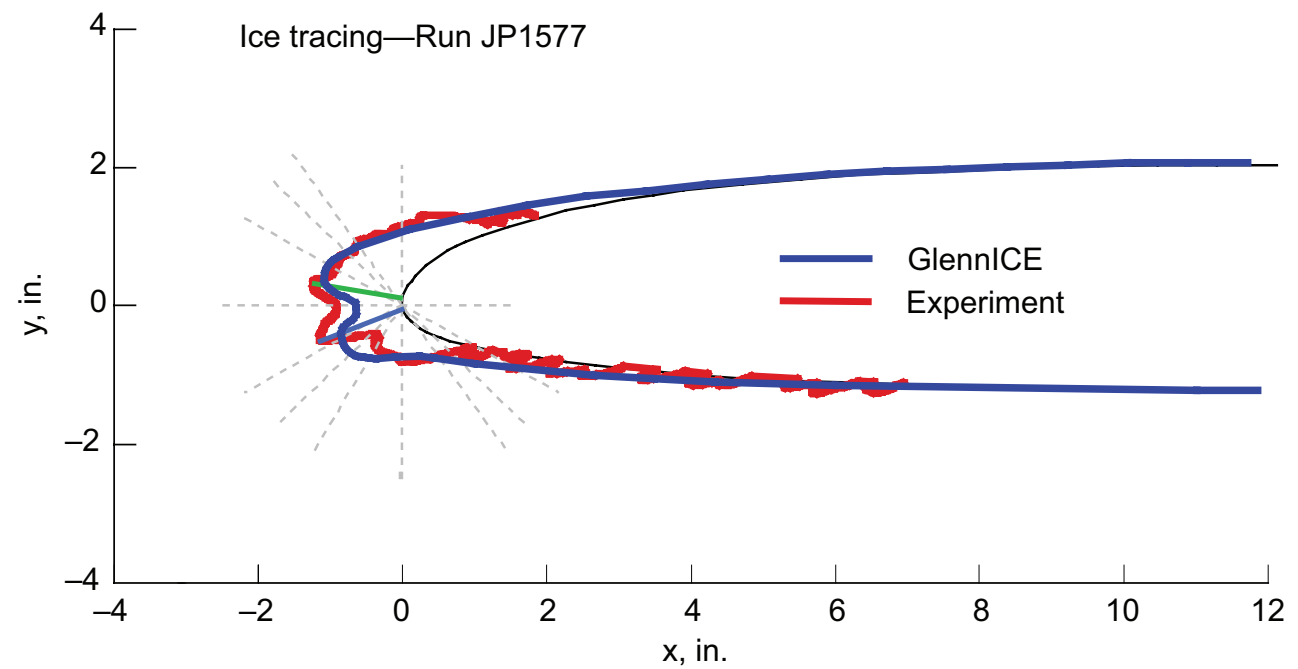

Figure 14.-Average comparison from measured parameters. 


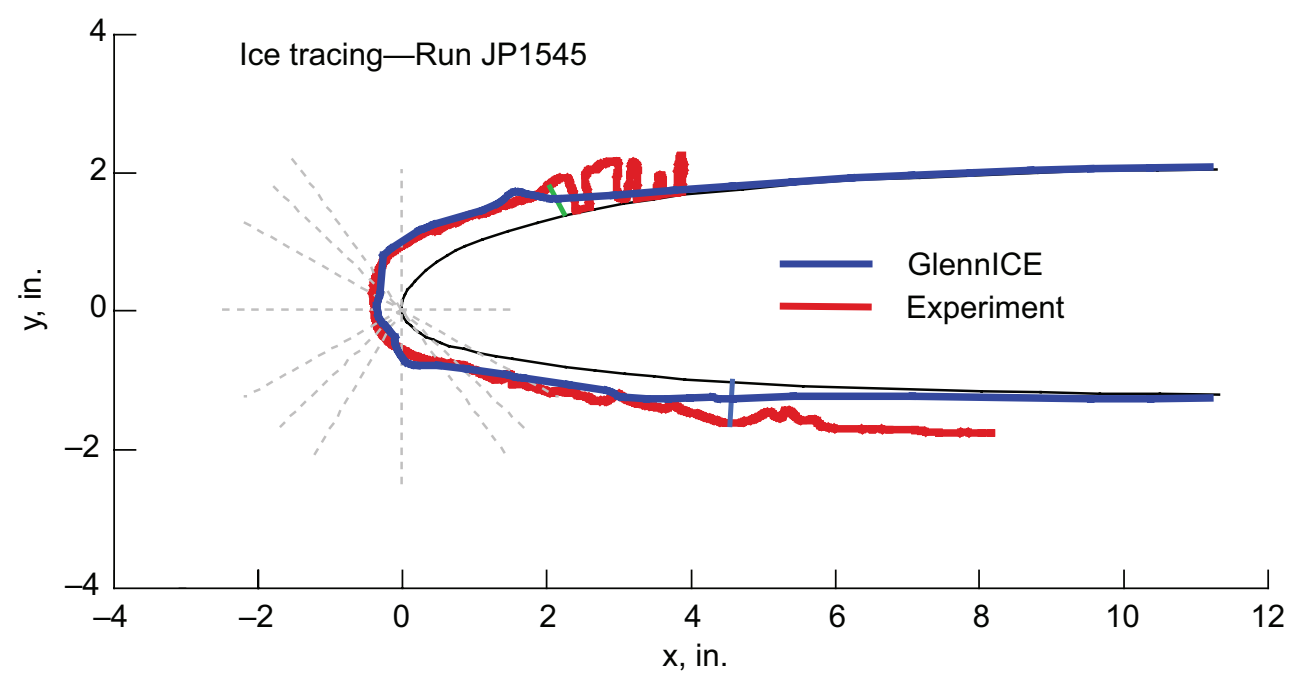

Figure 15.-Worst comparison based on measured parameters.

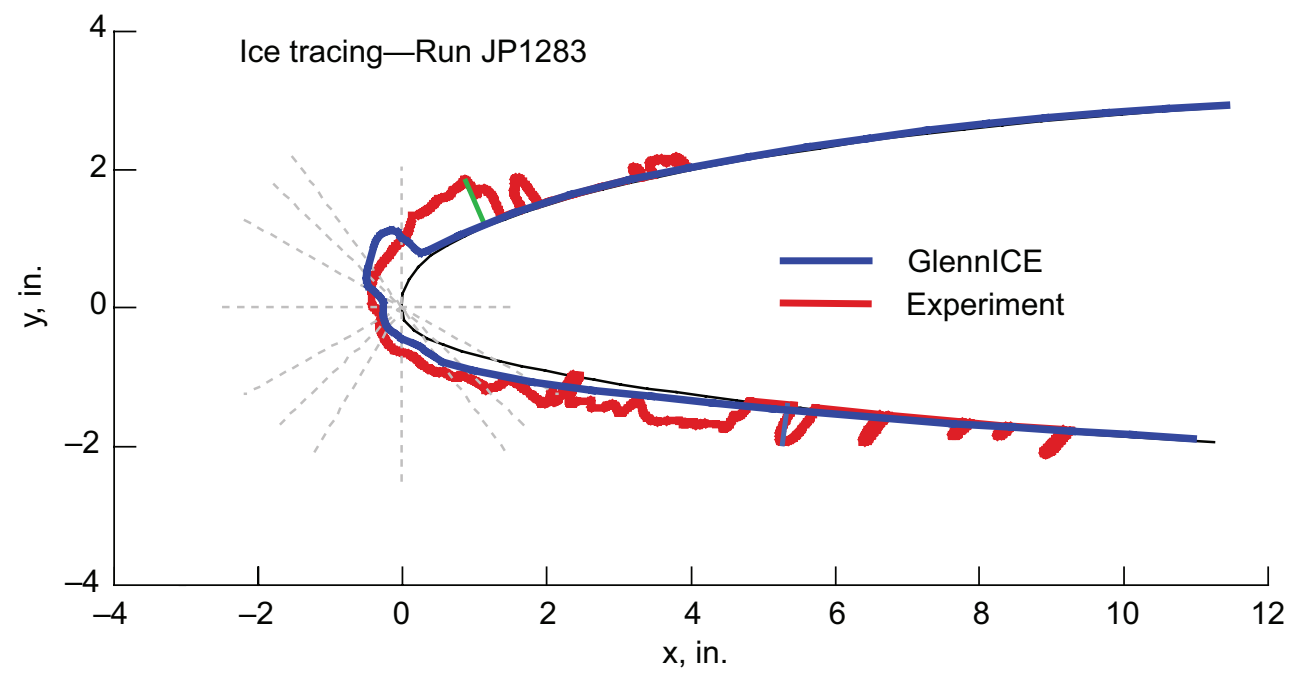

Figure 16.-Worst comparison No. 1 by qualitative observation.

experimental shape are slightly longer and closer together than the code results. It is not clear that in this case the difference would be aerodynamically significant. Figure 15 shows the ice shape that produces the "worst" comparison by the quantitative measures. However, as can be seen from the figure, this ice shape is not significantly worse than the previous comparisons. The parameters are worse primarily because of a difference in the assigned location for the lower ice horn. The lower horn from the experiment was judged to be at $x=4.5 \mathrm{in}$. while the "lower" horn generated by THICK for the code results was actually on the upper surface at $x=-0.2$ in., $y=0.75 \mathrm{in}$. While each individual measurement can be defended, the outcome results in a measured "difference" of $238^{\circ}$ in the reported horn angle, which is not representative of the general agreement between the two shapes. It should also be noted that the experimental ice shape clearly continues past the end of the template on the lower surface. This causes an erroneous difference in the reported icing limit as well. A more valid evaluation of which shapes compare well can unfortunately only be performed qualitatively at this time. A utility program was written that creates a Microsoft Word (Microsoft Corporation) document containing thumbnail pictures of each shape so that a quick qualitative comparison could be made. Figures 16 and 17 show two ice shapes that were judged to be qualitatively the worst. The first shape, from a NLF-0414 airfoil where $c=36$ in., $V=100 \mathrm{kts}, \alpha=2^{\circ}, T_{o}=-5^{\circ} \mathrm{F}$, 


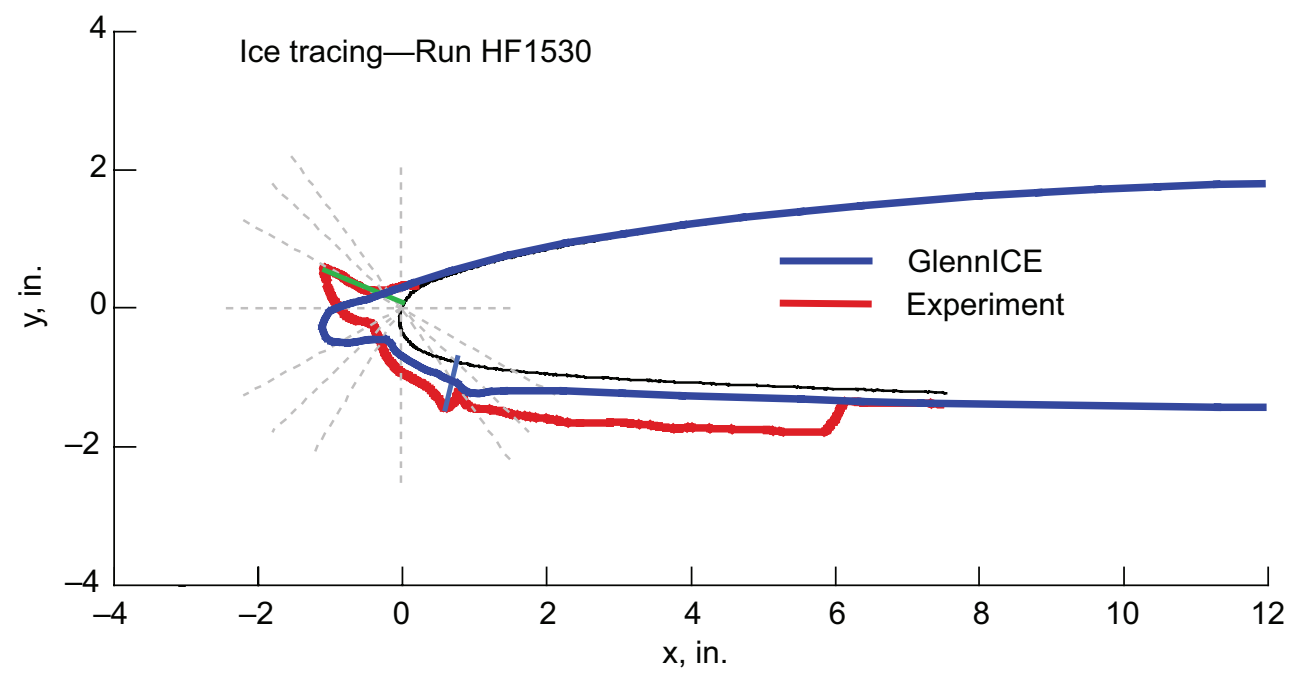

Figure 17.-Worst comparison No. 2 by qualitative observation.

$M V D=45 \mu \mathrm{m}, L W C=0.97 \mathrm{~g} / \mathrm{m}^{3}, t=10 \mathrm{~min}$, shows that the code can under predict ice feathers on the upper surface to a large enough degree such that it undoubtedly impacts the aerodynamics of the two shapes. The code was run with a monodispersed $M V D$ for this condition as well. The second shape, from a GLC-305 airfoil where $c=36$ in., $V=175 \mathrm{kts}, \alpha=6^{\circ}, T_{o}=-5^{\circ} \mathrm{F}, M V D=97 \mu \mathrm{m}, L W C=0.48 \mathrm{~g} / \mathrm{m}^{3}$, $t=10 \mathrm{~min}$, shows a typical result where potential flow predicts lower ice horns at high angles of attack. This type of result is sometimes seen in appendix $\mathrm{C}$ cases as well.

\section{Conclusions}

A new code (GlennICE) has been created for predicting ice accretion on 2D and 3D geometries. The intent of this process has been to streamline software development by creating a team-based rather than an individual-based development approach which has resulted in a more modularized program in which new algorithms can be easily added. The code keeps many of the same features as LEWICE and produces similar results for the cases compared thus far. A comparison with 2D experimental ice shape tracings confirms the fidelity of the new model. Comparisons in the SLD regime against a new set of experimental data confirm the accuracy of the SLD predictions for both LEWICE and GlennICE. A quantitative comparison with experimental ice shapes shows that the codes are as accurate in the SLD regime as they are in appendix $\mathrm{C}$ conditions for horn height, area and horn angle. Agreement is less accurate for icing limit. In general, the codes under predict the lower icing limit and show a higher variability in predicting the upper icing limit as compared to the agreement seen in appendix $\mathrm{C}$ conditions.

The process used to quantitatively compare ice shape features between two different profiles needs further improvement. The results from this and previous comparison efforts have shown that the current method can produce misleading results. While visual comparison of ice shape profiles can be used to qualitatively assess the degree of comparison, it is difficult to use such an approach to objectively determine whether changes in computational simulation methods have resulted in improvement. Currently a combination of visual inspection and ice shape feature measurement is the best approach to use for validation of computational ice growth simulation methods.

\section{References}

1. Potapczuk, M. and Gerhart, P., "Progress in development of a Naviér-Stokes solver for evaluation of iced airfoil performance," AIAA-85-0410. 
2. Wright, W., "Transient Two dimensional Heat Transfer Through a Composite Body with Application to Deicing of Aircraft Components," AIAA-88-0358.

3. Potapczuk, M., Bidwell, C., and Berkowitz, B., "Progress toward the development of an airfoil icing analysis capability," NASA Computational Fluid Dynamics Conference. Volume 1 Sessions 1-6 pp. 473-487, 1989.

4. Wright, W., "Two Dimensional Simulation of Electrothermal Deicing of Aircraft Components," J. Aircraft, V26, \#6, June 1989, pp. 554-562.

5. Potapczuk, M. and Bidwell, C., "Swept Wing Ice Accretion modeling," AIAA-90-0756.

6. Ruff, G. and Berkowitz, B., "Users manual for the NASA Lewis Ice Accretion Prediction Code (LEWICE)," NASA CR-185129, 1991.

7. Wright, W., "Numerical Simulation of Icing, Deicing, and Shedding," AIAA-91-0665.

8. Potapczuk, Mark G., "LEWICE E An Euler based ice accretion code," AIAA-92-0037.

9. Bidwell, C. and Potapczuk, M., "Users manual for the NASA Lewis three-dimensional ice accretion code (LEWICE 3D)," NASA TM-105974, 1993.

10. Potapczuk, M., "Naviér-Stokes analysis of airfoils with leading edge ice accretions," NASA CR-191008, 1993.

11. Al-Khalil, K.M., Keith, T.G., and De Witt, K.J. "Development of an Improved Model for Runback Water on Aircraft Surfaces," AIAA-92-0042, Jan. 1992.

12. Wright, W., "Advancements in the LEWICE Ice Accretion Model," AIAA-93-0171, Jan 1993.

13. Potapczuk, M., Al-Khalil, K., and Velazquez, M., "Ice accretion and performance degradation calculations with LEWICE NS," AIAA-93-0173.

14. Masiulaniec, C. and Wright, W., "User's Manual for the NASA Lewis Ice Accretion/Heat Transfer Prediction Code with Electrothermal Deicer Input," CR-4530 July 1994.

15. Wright, W., "Update to the NASA Lewis Ice Accretion Code LEWICE," CR-195387 Oct. 1994.

16. Bidwell, C. and Mohler, S., "Collection efficiency and ice accretion calculations for a sphere, a swept MS(1)-317 wing, a swept NACA-0012 wing tip, an axisymmetric inlet, and a Boeing 737-300," AIAA-1995-755.

17. Wright W., Bidwell, C., Potapczuk, M., Britton, R., and Al-Khalil, K. "Proceedings of the LEWICE Workshop," June 1995.

18. Wright, W. and Bidwell, C., "Additional improvements to the NASA Lewis ice accretion code LEWICE," AIAA-95-0752.

19. Wright, W., "Users Manual for the Improved NASA Lewis Ice Accretion Code LEWICE 1.6," CR-198355 June 1995.

20. Wright, W. and Potapczuk, M., "Comparison of LEWICE 1.6 \& LEWICE/NS w/experiment," AIAA-97-0175, Jan. 1997.

21. Wright, W., Al-Khalil, K., and Miller, D., "Comparison of LEWICE/Thermal Part II," AIAA-970050, Jan. 1997

22. Al-Khalil, K., Horvath, C., Miller, D., and Wright, W., "Comparison of LEWICE/Thermal Part III," AIAA-97-0051, Jan. 1997

23. Bidwell, C., Pinella, D., and Garrison, P., "Ice Accretion Calculations for a Commercial Transport Using the LEWICE3D, ICEGRID3D and CMARC Programs," AIAA-99-0250.

24. Baez, M., Vickerman, M., and Choo, Y., "SmaggIce User Guide," NASA/TM-2000-209793.

25. Chi, X., Zhu, B., Shih, T., Slater, J., Addy, H., and Choo, Y., "Computing Aerodynamic Performance of a 2D Iced Airfoil Blocking Topology and Grid Generation," AIAA-2002-0381.

26. Wright, W. "LEWICE 2.2 Capabilities and Thermal Validation," AIAA-2002-0383, Jan. 2002.

27. Vickerman, M., Choo, Y., Schilling, H., Baez, M. Braun, D., and Cotton, B., "Toward an efficient icing CFD process using an interactive software toolkit-SmaggIce 2D," AIAA-2002-0380.

28. Rutkowski, A., Wright, W., and Potapczuk, M., "Numerical Study of Droplet Splashing and Reimpingement," AIAA-2003-0388, Jan. 2003.

29. Wright, W. and Potapczuk, M., "Semi-Empirical Modeling of SLD Physics," AIAA-2004-0412. 
30. Wright, W., "An Evaluation of Jet Impingement Heat Transfer Correlations for Piccolo tube Application," AIAA-2004-0062, Jan. 2004.

31. Vickerman, M., Choo, Y., Schilling, H., Baez, M., Braun, D., and Cotton, B., "Further Progress in Software for Gridding 2D Iced Airfoils," AIAA-2005-1369.

32. Bidwell C., "Icing Calculations for a 3D, High-Lift Wing Configuration," AIAA-2005-1244.

33. Bhargava, C., Loth, E., and Potapczuk, M., "Numerical Simulation of Icing Clouds in the NASA Glenn Icing Research Tunnel," Journal of Aircraft, vol. 42, no. 6 (1442-1451), 2005.

34. Wright, W., "Further Refinement of the LEWICE SLD Model," AIAA-2006-0464, Jan. 2006.

35. Kreeger, R., Braun, D., Schilling, H., Vickerman, M., and Baez, M., "SmaggIce 2.0: Additional Capabilities for Interactive Grid Generation of Iced Airfoils," AIAA-2007-0502.

36. Levinson, L., Potapczuk, M., and Mellor, P., "Software development processes applied to computational icing simulation," AIAA-1999-0248.

37. Potapczuk, M., "A review of NASA Lewis' development plans for computational simulation of aircraft icing," AIAA-1999-243.

38. Van Zante, J.F., “A Database of Supercooled Large Droplet Ice Accretions," NASA/CR - 2007215020, Sept., 2007.

39. Wright, W.B. and Rutkowski, A., "Validation Results for LEWICE 2.0," NASA CR-208690, Nov. 1998.

40. Wright, W., "Validation Results for LEWICE 3.0," AIAA-2005-1243, Jan. 2005.

41. "In-flight Icing Encounter and Loss of Control Simmons Airlines, d.b.a. American Eagle Flight 4184 Avions de Transport Regional (ATR) Model 72-212, N401AM, Roselawn, Indiana October 31, 1994," NTSB Report Number: AAR-96-01.

42. G.A. Isaac, S.G. Cober, J.W. Strapp, D. Hudak, T.P. Ratvasky, D.L. Marcotte, and F. Fabry, "Preliminary Results from the Alliance Research Study (AIRS)." AIAA-2001-393, Jan. 2001.

43. M. Potapczuk, "Ice Mass Measurements: Implications for the Ice Accretion Process," AIAA-2003387, Jan. 2003.

44. T. Bond, M. Potapczuk, and D. Miller, “Overview of SLD Engineering Tool Development," AIAA2003-386, Jan. 2003.

45. Gent, J. Ford, R. Moser, and D. Miller, "Results from SLD Mass Loss Tests in the ACT Luton Icing Research Wind Tunnel," AIAA-2003-389, Jan. 6-9, 2003.

46. Tan, S.C. and Papadakis, M., "General Effects of Large Droplet Dynamics on Ice Accretion Modeling," AIAA-2003-392, Jan. 2003.

47. Papadakis, M., Elangonan, R., Freund, Jr., G.A., Breer, M., Zumwalt, G.W., and Whitmer, L., “An Experimental Method for Measuring Water Droplet Impingement Efficiency on Two- and ThreeDimensional Bodies," NASA CR-4257, Nov. 1989.

48. Papadakis, M., Breer, M., Craig, N., and Liu, X., "Experimental Water Droplet Impingement Data on Airfoils, Simulated Ice Shapes, an Engine Inlet and a Finite Wing," NASA CR-4636, DOT/FAA/CT-TN93/18, Dec. 1994.

49. Papadakis, M., Hung, K.E., Vu, G.T., Yeong, H.W., Bidwell, C.S., Breer, M.D., and Bencic, T.J., "Experimental Investigation of Water Droplet Impingement on Airfoils, Finite Wings, and an S-Duct Engine Inlet," NASA/TM-2002-211700, Oct. 2002.

50. Bush, R.H., Power, G.D., and Towne, C.E., "WIND: The Production Flow Solver of the NPARC Alliance," AIAA-98-0935, Jan. 1998.

51. NPARC Alliance Home Page, http://web.arnold.af.mil/nparc/index.html.

52. Thompson, D.S. and Soni, B.K., "ICEG2D: A Software Package for Ice Accretion Prediction," AIAA 2003-1070, Jan. 2003.

53. Schlichting, H., "Boundary Layer Theory," McGraw-Hill, Seventh Edition, pp. 712, 1987.

54. Owen, P. and Thompson, W., "Heat Transfer Across Rough Surfaces," J. Fluid Mechanics, vol. 15, pp. 321-334, 1943.

55. Press, W., Teukowsky, S., Vettering, W., and Flannery, B., "Numerical Recipes in Fortran," Cambridge University Press, 2nd Edition, pp. 118-122, 1992. 
56. Messinger, B., "Equilibrium Temperature of an Unheated Icing Surface as a Function of Air Speed," J. Aeronaut. Sci., vol. 20, no. 1, Jan. 1953, pp. 29-42.

57. Cansdale, J.T. and R.W. Gent, "Ice Accretion on Aerofoils in Two-Dimensional Compressible Flow -A Theoretical Model," Royal Aircraft Establishment Technical Report 82128, 1983.

58. Gent, R.W., "TRAJICE2-A Combined Water Droplet Trajectory and Ice Accretion Prediction Program for Aerofoils," DRA Technical Report TR 90054. Nov. 1990.

59. Brahimi, M.T., Tran, P., Tezok, F., and Paraschivoiu, I., "Numerical simulation of in-flight aircraft icing"” ICAS, Congress, 20th, Naples, Italy, Proceedings. Vol. 2; UNITED STATES; 8-13 Sept. 1996. pp. 1522-1532. 1996.

60. Myers, T.G. and Hammond, D.W., "Ice and Water Film Growth from Incoming Supercooled Droplets,” Intl. J. of Heat and Mass Transfer, vol. 42, pp. 2233-2242, 1999.

61. Myers, T.G., Charpin, J.P.F., and Chapman, S.J., "The Flow and Solidification of a Thin Fluid Film on an Arbitrary Three-dimensional Surface," Phys. of Fluids, Vol. 14, No. 8, pp. 2788-2804, Aug. 2002.

62. Bourgault, Y., Boutanios, Z., and Habashi, W., "FENSAP-ICE's Three-Dimensional In-Flight Ice Accretion Module, ICE3D," Journal of Aircraft, vol. 37 no. 1 (95-103) 2000.

63. Beaugendre, H., Morency, F., and Habashi, W.G., "FENSAP-ICE's three-dimensional in-flight ice accretion module: ICE3D," Journal of Aircraft. Vol. 40, no. 2, pp. 239-247. Mar.-Apr. 2003

64. D. Anderson and J. Tsao, "Additional Results of Ice-Accretion Scaling at SLD Conditions," AIAA2003-390, Jan. 6-9, 2003.

65. World Meteorological Organization, General meteorological standards and recommended practices, Appendix A, WMO Technical Regulations, WMO-No. 49, corrigendum, August 2000.

66. Tsao, J.C. and Rothmayer, A.P., "Triple-deck simulation of surface glaze ice accretion," AIAA2000-234

67. Rothmayer, A., "Stagnation Point Icing," AIAA-2006-1081.

68. Shin, J. and Bond, T.H., "Results of an icing test on a NACA 0012 airfoil in the NASA Lewis Icing Research Tunnel," AIAA-1992-647.

69. Shin, J. and Bond, T.H., "Repeatability of ice shapes in the NASA Lewis Icing Research Tunnel," Journal of Aircraft, vol. 31 no. 5 (1057-1063), 1994.

70. Tsao, J. and Anderson, D., "Latest Developments in SLD Scaling," AIAA-2005-5187.

71. Miller, D.R., Addy, H.E., and Ide, R., "A Study of Large Droplet Ice Accretions in the NASA Glenn IRT at Near-Freezing Conditions," AIAA-96-0934.

72. Addy, G.E., Potapczuk, M.G., and Sheldon, D., "Modern Airfoil Ice Accretions," AIAA-97-0174, Jan. 1997.

73. Addy, G., IRT Modern Airfoils Update Test Entry, Feb. 1998.

74. Anderson, D., IRT Scaling Test Entry, June 1996.

75. Addy, G., IRT Calibration Test Entry, Feb. 1996.

76. Van Zante, J.F., IRT Ice Shape Comparison Tests, 1996-2006.

77. Chen, S. and Langhals, T., "Experimental Validation on the Modification Techniques Developed for the New Scaling Methods," IRT Test Entry, Jan. 1999.

78. Reehorst, A., Chung, J., Potapczuk, M., and Choo, Y., "The Operational Significance of an Experimental and Numerical Study of Icing Effects on Performance and Controllability," AIAA-990374, Jan. 1999.

79. Addy, H.E., "Ice Accretions and Icing Effects for Modern Airfoils," NASA/TP-2000-210031.

80. Anderson, D., "Effect of velocity in icing scaling tests," AIAA-2000-0236.

81. Anderson, D., "Acceptable tolerances for matching icing similarity parameters in scaling applications," AIAA-2001-832.

82. Anderson, D., and Feo, A., "Ice-accretion scaling using water-film thickness parameters," AIAA2002-522.

83. Tsao, J. and Anderson, D., “Additional Study of MVD Effects on Ice Shapes,” AIAA-2004-0413. 
84. Miller, D., Potapczuk, M., and Langhals, T., "Preliminary Investigation of Ice Shape Sensitivity to Parameter Variations," AIAA-2005-0073.

85. Tsao, J. and Anderson, D., "Further Assessment of MVD Effects in SLD Applications," AIAA2005-0072.

86. Miller, D., Potapczuk, M., and Langhals, T., "Additional Investigations of Ice Shape Sensitivity to Parameter Variations," AIAA-2006-0469.

87. Potapczuk, M. and Miller, D., "Numerical Simulation of Ice Shapes from a Bimodal Large Droplet Icing Cloud," AIAA-2006-0462. 


\begin{tabular}{|c|c|c|}
\hline \multicolumn{2}{|c|}{ REPORT DOCUMENTATION PAGE } & $\begin{array}{c}\text { Form Approved } \\
\text { OMB No. 0704-0188 }\end{array}$ \\
\hline \multicolumn{3}{|c|}{ 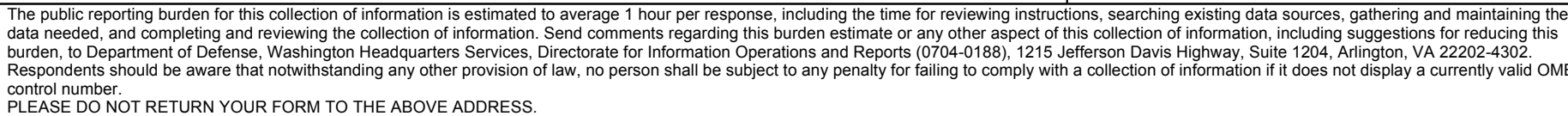 } \\
\hline $\begin{array}{l}\text { 1. REPORT DATE (DD-MM-YYYY) } \\
01-09-2008\end{array}$ & $\begin{array}{l}\text { 2. REPORT TYPE } \\
\text { Technical Memorandum }\end{array}$ & 3. DATES COVERED (From - To) \\
\hline \multirow{3}{*}{\multicolumn{2}{|c|}{$\begin{array}{l}\text { 4. TITLE AND SUBTITLE } \\
\text { Comparison of LEWICE and GlennICE in the SLD Regime }\end{array}$}} & 5a. CONTRACT NUMBER \\
\hline & & 5b. GRANT NUMBER \\
\hline & & 5c. PROGRAM ELEMENT NUMBER \\
\hline \multirow{3}{*}{\multicolumn{2}{|c|}{$\begin{array}{l}\text { 6. AUTHOR(S) } \\
\text { Wright, William, B.; Potapczuk, Mark, G.; Levinson, Laurie, H. }\end{array}$}} & 5d. PROJECT NUMBER \\
\hline & & 5e. TASK NUMBER \\
\hline & & $\begin{array}{l}\text { 5f. WORK UNIT NUMBER } \\
\text { WBS 457280.02.07.03.02 }\end{array}$ \\
\hline \multicolumn{2}{|c|}{$\begin{array}{l}\text { 7. PERFORMING ORGANIZATION NAME(S) AND ADDRESS(ES) } \\
\text { National Aeronautics and Space Administration } \\
\text { John H. Glenn Research Center at Lewis Field } \\
\text { Cleveland, Ohio 44135-3191 }\end{array}$} & $\begin{array}{l}\text { 8. PERFORMING ORGANIZATION } \\
\text { REPORT NUMBER } \\
\text { E-16417 }\end{array}$ \\
\hline \multirow{2}{*}{\multicolumn{2}{|c|}{$\begin{array}{l}\text { 9. SPONSORING/MONITORING AGENCY NAME(S) AND ADDRESS(ES) } \\
\text { National Aeronautics and Space Administration } \\
\text { Washington, DC 20546-0001 }\end{array}$}} & $\begin{array}{l}\text { 10. SPONSORING/MONITORS } \\
\text { ACRONYM(S) } \\
\text { NASA }\end{array}$ \\
\hline & & $\begin{array}{l}\text { 11. SPONSORING/MONITORING } \\
\text { REPORT NUMBER } \\
\text { NASA/TM-2008-215174; AIAA-2008- } \\
0439\end{array}$ \\
\hline \multicolumn{3}{|c|}{$\begin{array}{l}\text { 12. DISTRIBUTION/AVAILABILITY STATEMENT } \\
\text { Unclassified-Unlimited } \\
\text { Subject Categories: } 01,03 \text {, and } 59 \\
\text { Available electronically at http://gltrs.grc.nasa.gov } \\
\text { This publication is available from the NASA Center for AeroSpace Information, 301-621-0390 }\end{array}$} \\
\hline
\end{tabular}

\begin{tabular}{|l|}
\hline 13. SUPPLEMENTARY NOTES \\
\\
\hline 14 ABSTRACT
\end{tabular}

A research project is underway at the NASA Glenn Research Center (GRC) to produce computer software that can accurately predict ice growth under any meteorological conditions for any aircraft surface. This report will present results from two different computer programs. The first program, LEWICE version 3.2.2, has been reported on previously. The second program is GlennICE version 0.1. An extensive comparison of the results in a quantifiable manner against the database of ice shapes that have been generated in the GRC Icing Research Tunnel (IRT) has also been performed, including additional data taken to extend the database in the Super-cooled Large Drop (SLD) regime. This paper will show the differences in ice shape between LEWICE 3.2.2, GlennICE, and experimental data. This report will also provide a description of both programs. Comparisons are then made to recent additions to the SLD database and selected previous cases. Quantitative comparisons are shown for horn height, horn angle, icing limit, area, and leading edge thickness. The results show that the predicted results for both programs are within the accuracy limits of the experimental data for the majority of cases.

\section{SUBJECT TERMS}

Aircraft icing

\begin{tabular}{|c|c|c|c|c|c|}
\hline \multicolumn{3}{|c|}{ 16. SECURITY CLASSIFICATION OF: } & \multirow{2}{*}{$\begin{array}{l}\text { 17. LIMITATION OF } \\
\text { ABSTRACT } \\
\text { UU }\end{array}$} & \multirow{2}{*}{$\begin{array}{l}\text { 18. NUMBER } \\
\text { OF } \\
\text { PAGES } \\
30\end{array}$} & \multirow{2}{*}{$\begin{array}{l}\text { 19a. NAME OF RESPONSIBLE PERSON } \\
\text { STI Help Desk (email:help@ } \text { sti.nasa.gov) } \\
\text { 19b. TELEPHONE NUMBER (include area code) } \\
\text { 301-621-0390 }\end{array}$} \\
\hline $\begin{array}{l}\text { a. REPORT } \\
U\end{array}$ & $\begin{array}{l}\text { b. ABSTRACT } \\
U\end{array}$ & $\begin{array}{l}\text { c. THIS } \\
\text { PAGE } \\
U\end{array}$ & & & \\
\hline
\end{tabular}



